\title{
Francisco José de Caldas Tenorio (1768-1816): antología de artículos sobre su vida y obra en la Revista de la Academia Colombiana de Ciencias Exactas, Físicas y Naturales
}

\author{
Alberto Gómez-Gutiérrez \\ Instituto de Genética Humana, Facultad de Medicina, Pontificia Universidad Javeriana, Bogotá, Colombia
}

Con ocasión del 250 aniversario del nacimiento de Francisco José de Caldas, precursor de la ciencia en Colombia, se presenta una antología comentada de los artículos sobre su vida y obra que fueron publicados en la Revista de la Academia Colombiana de Ciencias Exactas, Físicas y Naturales entre 1936, fecha de su fundación, y $2017^{1}$.

Debe advertirse que al ser Caldas referente histórico de diferentes disciplinas científicas en Colombia, y al haber sido designado como epónimo institucional y epíteto taxonómico, se ha optado por seleccionar para la presente antología exclusivamente aquellos artículos que mencionan a Francisco José de Caldas como individuo y desarrollan en torno a él conceptos y argumentos relativos a la historia de la ciencia nacional. No se incluyen artículos asociados a otros naturalistas contemporáneos de Caldas como Mutis y Humboldt, con la excepción del "Prefacio" (o "Prefación", como Caldas lo denominó originalmente), que el payanés dedicó a la "Geografía de las Plantas" del prusiano. Tampoco a los libros que tratan sobre Caldas publicados con fondos de la Academia de Ciencias - principalmente por los académicos Alfredo Bateman, Jorge Arias de Greiff y Santiago Díaz-Piedrahita, ${ }^{2}$ solos o en colaboración con otros autores-, los cuales se listan en la Tabla 1.

En la antología referida se relacionan también cinco artículos póstumos firmados por Caldas que fueron publicados por la Academia a partir de 1936 (Tabla 2). El primero de estos hizo parte del número 4 del volumen 1, con fecha de octubre-diciembre de 1937, y contiene la "Memoria sobre el estado de las quinas en general y en particular sobre

\footnotetext{
${ }^{1}$ El presente artículo corresponde a un resultado preliminar de las indagaciones del autor sobre fuentes primarias y secundarias de la obra de Francisco José de Caldas en el marco del proyecto de edición comentada de un manuscrito inédito del payanés titulado Viaje a Ibarra, recuperado recientemente por la Pontificia Universidad Javeriana en una librería-anticuario de París. Véase: Gómez-Gutiérrez (2016[b], 380-381).

${ }^{2}$ Los académicos Arias de Greiff, Bateman y Díaz-Piedrahita publicaron síntesis biográficas complementarias en la Academia Colombiana de Historia, y con otros editores. Estas son, en orden cronológico: Arias de Greiff, Bateman, Fernández Pérez \& Soriano Lleras (1966); Bateman (1969, 1970, 1978); Arias de Greiff (1994); Díaz-Piedrahita $(1994,1997)$.
}

las de Loja", cuya fecha original se reporta en Quito en marzo 16 de 1805 . Una sola ilustración acompaña el texto, y esta corresponde a la "Carta topográfica de las cercanías de Loja que producen la Cinchona officinalis levantada por F. J. de Caldas en octubre de 1804" (Figura 1). ${ }^{3}$

Además de precisar los términos de altitud (300 $1.553,7$ toesas sobre el nivel del mar) y latitud $\left(5^{\circ}\right.$ boreal - $12^{\circ}$ austral), Caldas concluyó así su Memoria sobre las quinas de Loja:

De todo lo dicho hasta aquí resulta que en toda la América Meridional, solo en las 200 leguas de las inmediaciones de Loja se halla la verdadera Cinchona officinalis, la única que se remite por cuenta de S[u] M[ajestad] a la Botica Real; que acotándola bajo los límites que prescribe la carta adjunta, corrigiendo algunos abusos, y sobre todo, promoviendo los plantíos, pueden proveer para siempre estos bosques, no solo de las 4[00] - 500 arrobas que se extraen hoy, sino una cantidad mucho mayor; que animando los trasplantes a otros lugares análogos del Reino, se multiplicará este específico prodigiosamente con notables ventajas de los Pueblos y del Rey; que sujetando al Profesor de Loja a las luces y dirección del célebre Mutis, saldrá del letargo en que hace trece años se halla sepultado; se perfeccionarán, o mejor decir, se echarán los fundamentos a una Administración abandonada hasta hoy al capricho y a la ignorancia de los Corregidores de esa Ciudad; que las otras especies de Quinas inferiores en virtud pueden sin perjuicio de S[u] M[ajestad] dejarse en manos de los vasallos; que esta providencia digna de un Soberano clemente sacará a muchas familias de la miseria y reanimará considerablemente el comercio moribundo de la Provincia de Quito. En fin, que, para impedir los cortes indiscretos, y los abusos de los particulares, se formen ordenanzas que prescriban el método, la cantidad, el tiempo en que deben verificarse los acopios. ${ }^{4}$

Esta Memoria fue presentada en ese mismo número en medio de las notas editoriales de Jorge Álvarez Lleras (1885-1952), bajo el subtítulo de "La quinología de Caldas

\footnotetext{
${ }^{3}$ Las figuras que ilustran el presente artículo (con excepción de la Figura 6) fueron tomadas directamente de los artículos publicados en los números originales de la Revista de la Academia Colombiana de Ciencias Exactas, Físicas y Naturales. En este caso, véase: Caldas, [1805] 1937; 1(4): 326-333, inserto.

${ }^{4}$ Caldas, [1805] 1937; 1(4): 333. En: http://dx.doi.org/10.18257/ raccefyn. 734
} 
Tabla 1. Libros que tratan sobre Caldas editados o coeditados por la Academia de Ciencias Exactas, Físicas y Naturales

\begin{tabular}{cll}
\hline Año & Título & Autores o editores \\
\hline 1978 & Cartas de Caldas & Alfredo Bateman; Jorge Arias de Greiff \\
\hline 1991 & La botánica en Colombia, hechos notables en su desarrollo & Santiago Díaz-Piedrahita \\
\hline 1994 & La astronomía en Colombia & Jorge Arias de Greiff \\
\hline 2006 & La obra cartográfica de Francisco José de Caldas & $\begin{array}{l}\text { Mauricio Nieto Olarte; Santiago Muñoz Arbeláez; } \\
\text { Santiago Díaz-Piedrahita; Jorge Arias de Greiff }\end{array}$ \\
\hline 2010 & Hombres de ciencia e independencia & Santiago Díaz-Piedrahita \\
\hline 2016 & Cartas de Caldas ilustradas & Nataliya Savitskaya; Diego Caldas Varona \\
2016 & $\begin{array}{l}\text { Ensayo de una memoria sobre un nuevo método de medir las } \\
\text { montañas por medio del termómetro }\end{array}$ & $\begin{array}{l}\text { Darío Valencia Restrepo (ed.); Jorge Arias de Greiff; } \\
\text { Víctor Manuel Albis; Regino Martínez-Chavanz; } \\
\text { Luis Carlos Arboleda }\end{array}$ \\
\hline 2016 & Francisco José de Caldas, 1768-1816. Bicentenario de su muerte & $\begin{array}{l}\text { Darío Valencia Restrepo (ed.); Jorge Arias de Greiff; } \\
\text { Luis Carlos Arboleda; Gonzalo Andrade, et al. }\end{array}$ \\
\hline
\end{tabular}

Tabla 2. Artículos de y sobre Caldas en la Revista de la Academia de Ciencias Exactas, Físicas y Naturales

\begin{tabular}{|c|c|c|}
\hline Año (volumen) & Título & Autor \\
\hline \multirow[t]{2}{*}{ 1936-1937 (I) } & La quinología de Caldas y un nuevo aspecto científico de este prócer & Jorge Álvarez Lleras \\
\hline & Memoria sobre el estado de las quinas en general y en particular sobre las de Loja & Francisco José de Caldas \\
\hline \multirow[t]{9}{*}{1938 (II) } & Los escritos de Caldas & Jorge Álvarez Lleras \\
\hline & Carta inédita del sabio Caldas al doctor Antonio Arboleda & Francisco José de Caldas \\
\hline & $\begin{array}{l}\text { La vida de Caldas como ejemplo de lo que ha sido hasta ahora la ciencia para el país } \\
\text { colombiano }\end{array}$ & Jorge Álvarez Lleras \\
\hline & Estudios seleccionados referentes a astronomía, meteorología y física & Francisco José de Caldas \\
\hline & Nota de la dirección & Jorge Álvarez Lleras \\
\hline & Inscripción conmemorativa de los trabajos de la Misión al ecuador & Georges Perrier \\
\hline & Explicación de Caldas referente a la lápida de Cuenca & Francisco José de Caldas \\
\hline & Artículo necrológico del Sr Dr José Celestino Mutis & Francisco José de Caldas \\
\hline & $\begin{array}{l}\text { Memoria histórica sobre la vida, carácter, trabajos científicos y literarios, } \\
\text { y servicios patrióticos de Francisco José de Caldas }\end{array}$ & Lino de Pombo \\
\hline $1945(\mathrm{VI})$ & Sesión solemne de la Sociedad Colombiana de Ingenieros en honor de Caldas & Jorge Álvarez Lleras \\
\hline 1950 (VIII) & Prefacio a la geografía de las plantas de Alexander von Humboldt & Francisco José de Caldas \\
\hline \multirow[t]{2}{*}{1951 (VIII) } & Homenaje al sabio Francisco José de Caldas & Jorge Álvarez Lleras \\
\hline & El amor y la sabiduría de Francisco José de Caldas & Luis María Murillo \\
\hline 1952 (VIII) & Caldas y el hipsómetro & Alfredo Bateman \\
\hline \multirow[t]{2}{*}{$1959(\mathrm{X})$} & Caldas y Humboldt & Alfredo Bateman \\
\hline & La ciencia y la historia & Enrique Pérez Arbeláez \\
\hline \multirow[t]{3}{*}{$1960(\mathrm{XI})$} & Francisco José de Caldas & Luis María Murillo \\
\hline & Caldas y los orígenes eurocriollos de la geobotánica & Pablo Vila \\
\hline & Francisco José de Caldas, periodista & $\begin{array}{l}\text { Luis Martínez Delgado y } \\
\text { Sergio Elías Ortiz }\end{array}$ \\
\hline 1992 (XVIII) & Francisco José de Caldas y la botánica & Santiago Díaz-Piedrahita \\
\hline $1996(X X)$ & El método de Caldas para medir la elevación de las montañas & Jorge Arias de Greiff \\
\hline \multirow[t]{3}{*}{$2016(\mathrm{XL})$} & Caldas, matematización de la naturaleza y sentimiento telúrico & Luis Carlos Arboleda \\
\hline & Las mariposas de Francisco José de Caldas y Thenorio & Gonzalo Andrade \\
\hline & $\begin{array}{l}\text { Un manuscrito póstumo e inédito de } 200 \text { años: Cuaderno de viajes } \\
\text { y observaciones de Francisco José de Caldas entre } 1802 \text { y } 1807\end{array}$ & Alberto Gómez Gutiérrez \\
\hline 2017 (XLI) & Caldas y el gran cometa de 1807 & Gregorio Portilla \\
\hline
\end{tabular}




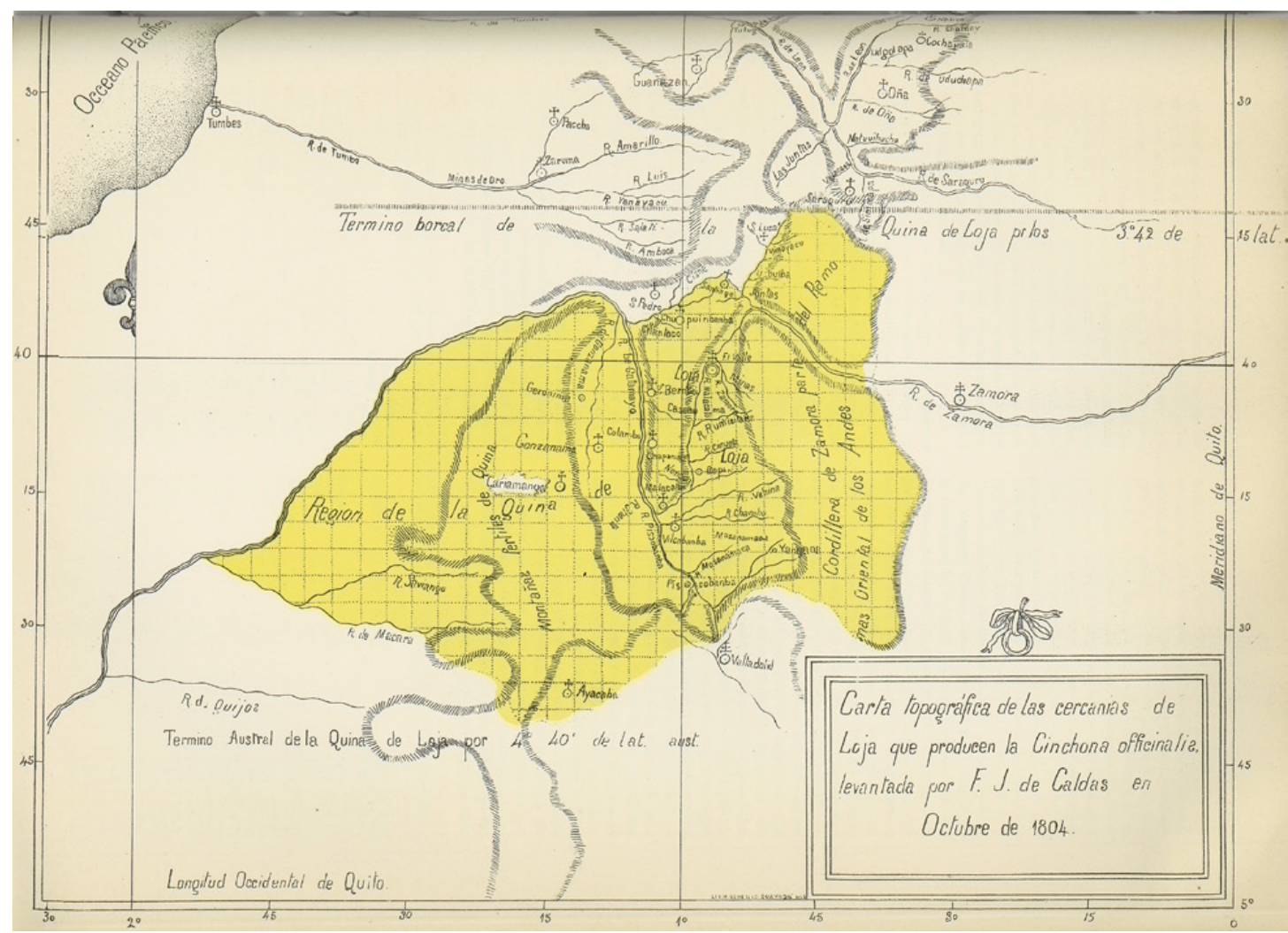

Figura 1. Carta topográfica de las cercanías de Loja que producen la Cinchona officinalis levantada por F. J. de Caldas en octubre de 1804. Tomada de la transcripción del manuscrito original titulado "Memoria sobre el estado de las Quinas en general y en particular sobre la de Loxa”, en: Federico González Suárez. Un opúsculo inédito de don Francisco José de Caldas (Guayaquil, 1907).

y un nuevo aspecto científico de este prócer”, y hacía parte de una sucesión de artículos sobre la Expedición Botánica, específicamente sobre la quina, que publicó la Academia partiendo de la reproducción del texto decimonónico de José Jerónimo Triana Silva (1828-1890) titulado "La quinología de Mutis". El editor incluyó un extracto de la Introducción a la Memoria de Caldas que fuera publicada por primera vez en Guayaquil en 1907 por el arzobispo Federico González Suárez (1844-1917), titulada "Un opúsculo inédito de don Francisco José de Caldas". ${ }^{5}$

La segunda referencia de los académicos a Caldas, después de la que correspondió a su Memoria póstuma sobre las quinas, apareció en las "Notas editoriales" del número 5 en el volumen 2 de 1938, bajo el descriptor de "Los escritos de Caldas". En esta sección editorial se enumeraron 22 textos "atendiendo al orden cronológico de ellos", seguidos por ocho escritos más, cuyo listado se cierra con la transcripción de la "[Copia de una] carta inédita del sabio dirigida al doctor Antonio Arboleda, [de Popayán"] remitida a la Academia por uno de sus descendientes, don Vicente J. Arboleda C., "con el objeto de que sea conocida en su

\footnotetext{
${ }^{5}$ Álvarez Lleras, 1937; 1(4):306-309. En: http://dx.doi.org/10.18257/ raccefyn. 735
}

intimidad". ${ }^{6}$ Esta epístola haría parte de las 195 Cartas de Caldas que fueron posteriormente editadas en el año 1978 por los académicos Alfredo Bateman y Jorge Arias de Greiff, y publicadas por la Academia de Ciencias. ${ }^{7}$ Los 30 textos (algunos de ellos compuestos) relacionados por Álvarez Lleras en este editorial de 1938, con la advertencia de que no se pretendía que esta fuera una lista exhaustiva de la obra caldasiana, son:

1. Ensayo de una Memoria sobre un nuevo método de medir las montañas por medio del termómetro y el agua hirviendo ([1802] 1819)

2. Estado de la geografía del Virreinato de Santa $\mathrm{Fe}$ de Bogotá con relación a la economía y al comercio ([1807] 1808)

3. Descripción del Observatorio Astronómico de Bogotá (1808)

4. Discurso sobre la educación (1808)

5. El influjo del clima sobre los seres organizados (1808)

6. Artículo necrológico de don José Celestino Mutis (1808)

7. Tablas de observaciones meteorológicas - Eclipse total de Luna (1808) - Noticia meteorológica (1809)

${ }^{6}$ Caldas (1802), en Álvarez Lleras, 1938; 2(5): 3-5. En: http://dx.doi. org/10.18257/raccefyn.737

${ }^{7}$ Véase Caldas [1802] en Bateman y Arias, 1978, 135-139. 
8. Geografía de las plantas o cuadro físico de los Andes equinocciales - Notas (1809)

9. Elevación del pavimento del salón principal del Observatorio Astronómico de Bogotá (1809)

10. Memoria sobre el cultivo de la cochinilla y sobre la impor-tancia de trasplantar al Nuevo Reino la canela, el clavo, la nuez moscada y las demás especias del Asia (1810)

11. Memoria sobre el modo de cultivar la cochinilla (1810)

12. Memoria sobre la importancia de connaturalizar en el Nuevo Reino de Granada la vicuña del Perú y de Chile (1810)

13. Almanaque para el año 1811 (1810) - Almanaque parta $1812(1811)$

14. Cuadro físico de las regiones equinocciales - Notas Descripción y medidas del Salto de Tequendama (1810)

15. Estadística de Méjico, por el Barón de Humboldt Notas (1810)

16. Elogio histórico del Dr Dn Miguel Cabal (1810)

17. Viajes de Caldas ([1802-1804] 1843 -sic- $\left.^{8}\right)$

18. Memoria sobre el plan de viaje proyectado en Quito a la América Septentrional ([1802] 1849)

19. Representación dirigida al Secretario del Virrey de Bogotá ([1808] 1849)

20. Memoria sobre las Quinas de la Provincia de Loja en el Ecuador ([1805] 1907)

21. Memoria sobre la nivelación de las plantas que se cultivan en la vecindad del ecuador - Tabla de las alturas del barómetro en los puntos principales de la nivelación ([1803] 1906)

22. Viaje al norte de Santa Fe de Bogotá (1812)

A los ocho textos restantes se alude como que "se conservan ocultos, o acaso se han perdido sin remedio":

23. Dos volúmenes manuscritos, en los cuales hacía la narración de sus viajes y describía el estado de los pueblos de la parte meridional del Virreinato (1802-1804) ${ }^{9}$

24. Una Memoria sobre la geografía de las plantas ( $\sin$ fecha)

25. Numerosos apuntes recogidos para componer la gran obra botánica titulada Phytografia Aquatorialis (sin fecha)

26. Medidas barométricas numerosas (sin fecha)

27. Muchas cartas geográficas levantadas con mucha prolijidad (1802-1809) ${ }^{\mathbf{1 0}}$

\footnotetext{
${ }^{8}$ Se trata del año 1849 , año de la reedición de algunos textos de Caldas escogidos por Joaquín Acosta en compañía del librero Antoine Lasserre.

${ }^{9}$ Estos corresponden probablemente a los manuscritos titulados "Viaje a Cotacache" y "Viaje a Ibarra", que se conservan hoy en la Biblioteca Lilly de la Universidad de Indiana en Bloomington, Estados Unidos, y en la Biblioteca Alfonso Borrero Cabal, S. J. Sección de Libros Valiosos- de la Pontificia Universidad Javeriana en Bogotá, respectivamente.

${ }^{10}$ La obra cartográfica original de Caldas fue publicada por Mauricio Nieto Olarte en el 2006 con base en sus hallazgos en archivos españoles y colombianos. Véase Nieto (2006).
}

28. Un volumen de observaciones astronómicas (sin fecha)

29. Una obra sobre las quinas, cuyo título era Cinchonas ( $\sin$ fecha)

30. Según [José Manuel] Groot [y Urquinaona], el Diario político que comenzó a publicarse en Bogotá por orden de la Junta Suprema el año de 1810, fue redactado por Caldas y por [Joaquín] Camacho (sin fecha) ${ }^{11}$

Es importante, en este punto, incluir como referencia la Tabla de Contenido de la compilación de los 45 trabajos caldasianos que había publicado el historiador Eduardo Posada (1862-1942) en 1912 bajo el título de Obras de Caldas en el volumen IX de la colección denominada "Biblioteca de Historia Nacional". Estos son, en orden cronológico:

- Educación de menores (1793)

- Observaciones sobre la altura de Guadalupe (1801)

- Ensayo de una memoria sobre un nuevo método de medir las montañas y sobre el proyecto de una expedición científica (1802)

- Memoria sobre el origen del sistema de medir las montañas (1802)

- Memoria sobre el plan de un viaje de Quito á la América Septentrional (1802)

- Memoria sobre la nivelación de las plantas que se cultivan en la vecindad del Ecuador (1803)

- Discurso en elogio del doctor José C. Mutis (1803)

- Viaje de Quito á las costas del Océano Pacífico por Malbucho (1804)

- Carta del camino de Malbucho (1804)

- Viaje al corazón de Barnuevo (1804)

- Viajes al sur de Quito (1804)

- Viaje de Paute (1804)

- Cuenca (1804)

- Memoria sobre el estado de las quinas en general, y en particular sobre las de Loja (1805)

- Viaje de Quito á Popayán (1805)

- Estado de la geografía del Virreinato de Santafé ([1807] 1808)

- Descripción del Observatorio Astronómico de Santafé (1808)

- Artículo necrológico del señor J. C. Mutis (1808)

- Del influjo del clima sobre los seres organizados (1808)

- Observaciones meteorológicas (1808)

- Memorial al Secretario del Virreinato (1808)

- Prospecto del Semanario para 1809 (1809)

- Noticias meteorológicas (1809)

- Prefación á la Geografía de las plantas (1809)

- Notas á la misma (1809)

- Contestación á las censuras (1809)

- Respuesta al Aprendiz (1809)

- Elevación del pavimento del Observatorio (1809)

${ }^{11}$ Álvarez Lleras, 1938; 2(5): 2-3. En: http://dx.doi.org/10.18257/ raccefyn.736 
- Nuevo plan del Semanario para 1810 (1809)

- Epílogo (1809)

- [Primer] Informe al Virrey (1809)

- [Segundo] Informe al Virrey (1809)

- Memoria sobre la importancia del cultivo de la cochinilla (1810)

- Botánica - Pombea (1810)

- Memoria sobre el modo de cultivar la cochinilla (1810)

- Botánica - Consuegria (1810)

- Memoria sobre la importancia de connaturalizar en el Reino la vicuña del Perú y de Chile (1810)

- Preliminares para el almanaque de 1811 (1810)

- [Prefación del] Cuadro físico de las regiones ecuatoriales (1810)

- [Advertencia sobre la] Estadística de Méjico (1810)

- Elogio histórico del doctor don Miguel Cabal (1811)

- Almanaque para el año de 1812 (1811)

- Viaje al norte de Santafé de Bogotá (1812)

- Discurso [preliminar] en el cuerpo de Ingenieros de Antioquia (1814)

- Plan razonado de un cuerpo de ingenieros mineralógicos ([1802] s. f. $)^{12}$

Volviendo a la revista de la Academia Colombiana de Ciencias Exactas, Físicas y Naturales (ACCEFYN) en 1938, su segundo año de existencia, se publicó una nueva referencia de los académicos al payanés en las "Notas de la dirección" correspondientes al número 6 del volumen 2, coincidiendo con el cuarto centenario de la fundación de Bogotá. Después de una breve introducción sobre la importancia del Observatorio Astronómico Nacional como símbolo "de lo poco que en el campo científico se ha hecho" para justificar "el nombre de Atenas suramericana con que ingenios extranjeros han designado a Bogotá", y "como centro de la mayor parte de los trabajos científicos ejecutados en este país, ya directa o indirectamente", se explica que se ha optado, al "hacer la historia de las ciencias en Colombia" para dicha efemérides, por dedicar un número de la revista al Observatorio "fundado por Mutis y dirigido por Caldas"13 en su calidad de sede principal de ACCEFYN en ese entonces.

\footnotetext{
${ }^{12}$ Posada, Eduardo. Obras de Caldas. Bogotá: Imprenta Nacional, 1912. La autoría del último escrito incluido en esta antología ha sido controvertida y aclarada por el historiador José Antonio Amaya $(2004,78)$, en razón a sus referencias internas. Para consultar sucesivas compilaciones y comentarios de las obras de Caldas, además de su correspondencia (cuyos principales epistolarios se presentan en la Tabla 1), véase, en orden cronológico: Acosta (1849); Schumacher ([1884] 1986); Mendoza (1909); Posada (1917); Barreiro (1933); Bateman (1966, 1970); Chenu (1992); Appel (1994); Andress y Nieto (2013).

${ }^{13}$ Las frases citadas en comillas fueron tomadas de Álvarez Lleras, Jorge. "Notas de la dirección". Revista de la Academia Colombiana de Ciencias Exactas, Físicas y Naturales 1938; 2(6): 161. Cursivas propias. En: http://www.accefyn.com/revista/Vol_2/v2no6/Notas dela_direccion.pdf
}

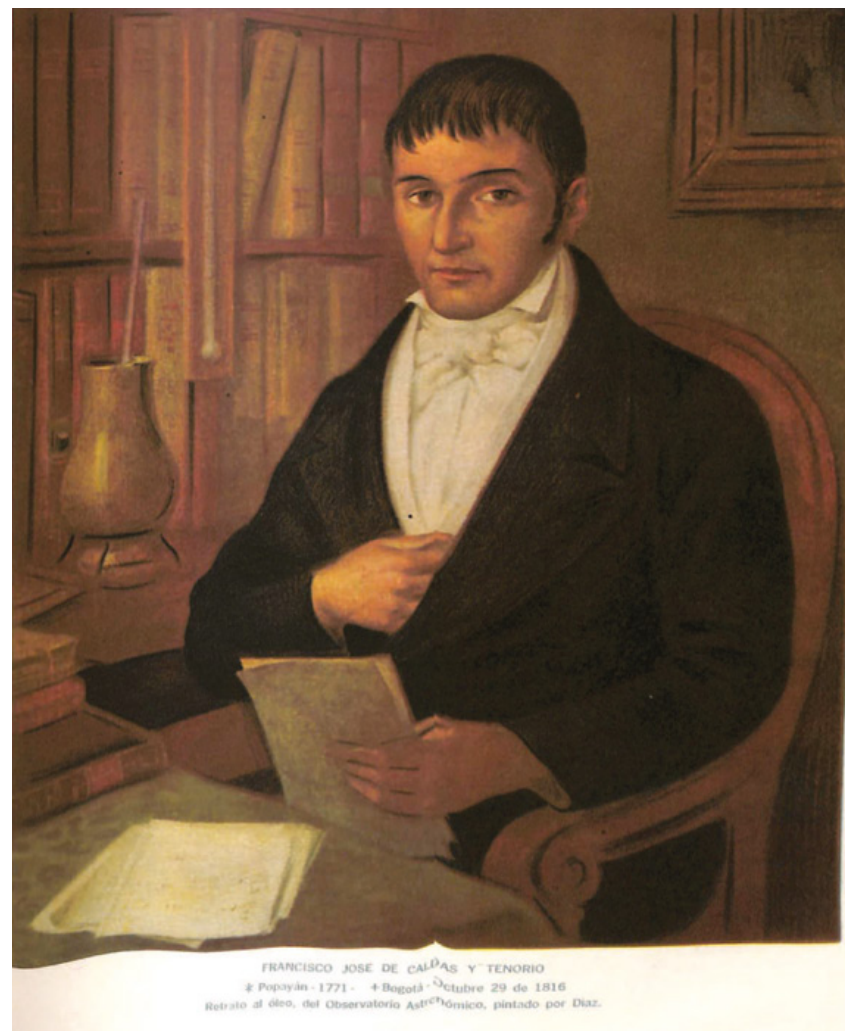

Figura 2. Retrato al óleo de Francisco José de Caldas. Autor: Miguel Díaz Vargas (1886-1956). Tomado de: Álvarez Lleras, Jorge. "Notas de la dirección". Revista de la Academia Colombiana de Ciencias Exactas, Físicas y Naturales 1938; 2(6): Inserto. El original se conserva en el Observatorio Astronómico.

Esta somera historia de las ciencias en Colombia, centrada en las labores del Observatorio Astronómico, incluye una sección completa subtitulada "La vida de Caldas como ejemplo de lo que ha sido hasta ahora la ciencia para el país colombiano" ${ }^{14}$ con la transcripción de algunos extractos de la carta de Caldas a Pascual Enrile, rogándole por su vida.

Cinco páginas después aparece una de las tres únicas ilustraciones del editorial conmemorativo, consistente en un retrato al óleo de Caldas "pintado por Díaz", con la referencia a los lugares y fechas de su nacimiento y muerte en el pie de imagen, así: "Popayán, 1771 (sic) - Bogotá, Octubre 29 de 1816" (Figura 2).

Los dos retratos complementarios en este sobrevuelo de la historia de la ciencia en Colombia fueron dispuestos, también a todo color, para Agustín Codazzi (1793-1859) y Julio Garavito Armero (1865-1920).

Más adelante, en esta misma revista conmemorativa, se incluyó un artículo titulado "Estudios seleccionados referentes a astronomía, meteorología y física" con la firma póstuma de "Francisco José de Caldas", a la que se agregó, como indicación de la vinculación institucional del autor en

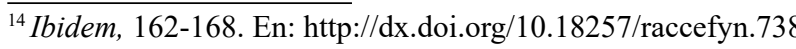


ese momento de su vida, el descriptor de "Primer Director del Observatorio Astronómico Nacional y segundo de Mutis en la Expedición Botánica". ${ }^{15}$

La selección de estos 13 textos estuvo a cargo del director de la revista, Jorge Álvarez Lleras, quien la justificó como la que daba "mejor idea de sus aficiones y capacidades científicas -esté ello reproducido muchas veces o sea de pocos conocido-". ${ }^{16}$ Estos son:

1. Descripción del Observatorio Astronómico de Santa Fe de Bogotá situado en el jardín de la Real Expedición Botánica (1808)

2. Elevación del pavimento del salón principal del Observatorio de Santa Fe de Bogotá (1809)

3. Observaciones de la aguja ([1802] s. f.)

4. Velocidad del sonido ([1802] s. f.)

5. Meteorología (1807)

6. Astronomía ([1802] s. f.)

7. Geografía del Reino - Latitud de Quito (s. f.)

8. Meteorología (1808)

9. Ensayo de una memoria sobre un nuevo método de medir las montañas por medio del termómetro y el agua hirviendo, seguida de un apéndice que contiene algunas observaciones muy importantes y útiles para la mejor inteligencia de dicha memoria ([1802] 1819) $)^{17}$

10. Apéndice ([1802] 1819) (Figura 3)

11. Carta del camino de Malbucho (1804)

12. [Adenda (1819)]

13. Almanaque de las Provincias Unidas del N[uevo] R[eino] de Granada para el año bisiesto de 1812, tercero de nuestra libertad, calculado por Francisco Josef de Caldas y Tenorio. Director del Observatorio Astronómico de Santafé de Bogotá (1811) (Figura 4).

En una "Nota de la Dirección"18 a pie de página de la transcripción de los "Estudios seleccionados referentes a astronomía, meteorología y física", Álvarez Lleras define a Caldas como lo contrario a un genio analítico: "genio intuitivo [...], físico [...], artífice [manual y] naturalista", y anuncia un extracto biográfico del prócer escrito por Lino de Pombo [O'Donnell (1797-1862)], el cual aparece en la "Sección de notas" de ese mismo número bajo el

\footnotetext{
${ }^{15}$ Caldas, [1802-1811] 1938; 2(5): 178-206. En: http://dx.doi. org/10.18257/raccefyn.739

${ }^{16}$ Con la misma intención, el académico Jorge Arias de Greiff presentaría años después, en el Boletín de Historia y Antigüedades de 1974, "Algunos documentos, desconocidos unos, y poco conocidos otros, pertinentes a don Francisco José de Caldas y Tenorio", todos ellos asociados con su correspondencia entre 1806 y 1816.

${ }^{17}$ Del ensayo de Caldas se conservan dos copias manuscritas originales: una en los fondos del Real Jardín Botánico de Madrid, y otra en la Biblioteca de la Universidad de Antioquia en Medellín. Para acceder a una copia facsimilar de este manuscrito, y a elaboraciones sucesivas, véase Valencia (2016[a, b, c] ).

${ }^{18}$ Álvarez Lleras, 1938; 2(6): 206. En: http://dx.doi.org/10.18257/ raccefyn. 740
}

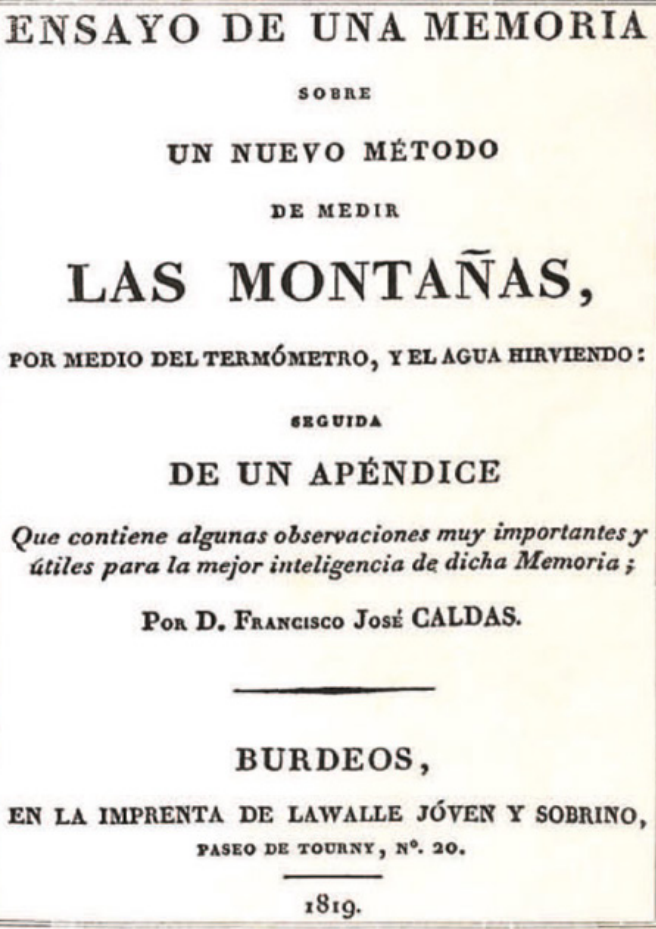

Figura 3. Portada de la Memoria de un nuevo método de medir las montañas por medio del termómetro y del agua hirviendo ([1802] 1819). Tomado de: Caldas, Francisco José. "Estudios seleccionados referentes a astronomía, meteorología y física". Revista de la Academia Colombiana de Ciencias Exactas, Físicas y Naturales 1938; 2(5): Inserto.

subtítulo "Memoria histórica sobre la vida, carácter, trabajos científicos y literarios, y servicios patrióticos de Francisco José de Caldas". ${ }^{19}$

Este texto sucedió a la transcripción de la "Explicación de Caldas referente a la lápida de Cuenca" que él había recuperado en 1804 y trasladado motu proprio (sin autorización

\footnotetext{
${ }^{19}$ Pombo, [1852] 1938; 2(6): 329-337. En: http://dx.doi.org/10.18257/ raccefyn.744. Esta obra fue originalmente publicada por entregas en el periódico bogotano La Siesta en 1852, luego reproducida por primera vez en 1867 en la Historia de la Literatura en la Nueva Granada de José María Vergara y Vergara, y por segunda vez en el tomo VI de la Revista de Instrucción Pública de Colombia en 1896. En el siglo XX esta misma obra tuvo varias reproducciones cuyo estudio, en palabras del matemático Luis Carlos Arboleda, "permitiría comprender hasta qué punto esta Memoria fue determinante en la formación histórica de la [posteridad de Caldas] que se fue sucesivamente [consolidando] en el siglo XX". La secuencia de las publicaciones de esta Memoria histórica de Pombo, así como la frase que va en comillas, corresponden a la comunicación personal del profesor Arboleda al autor, después de la lectura el primer borrador del presente artículo. Las más recientes reediciones de esta Memoria fueron publicadas por Mauricio Nieto en el Instituto Caro y Cuervo (2016), y por Carlos Cuartas en la Pontificia Universidad Javeriana (2016, 9-66), con ocasión del bicentenario de la muerte del payanés.
} 


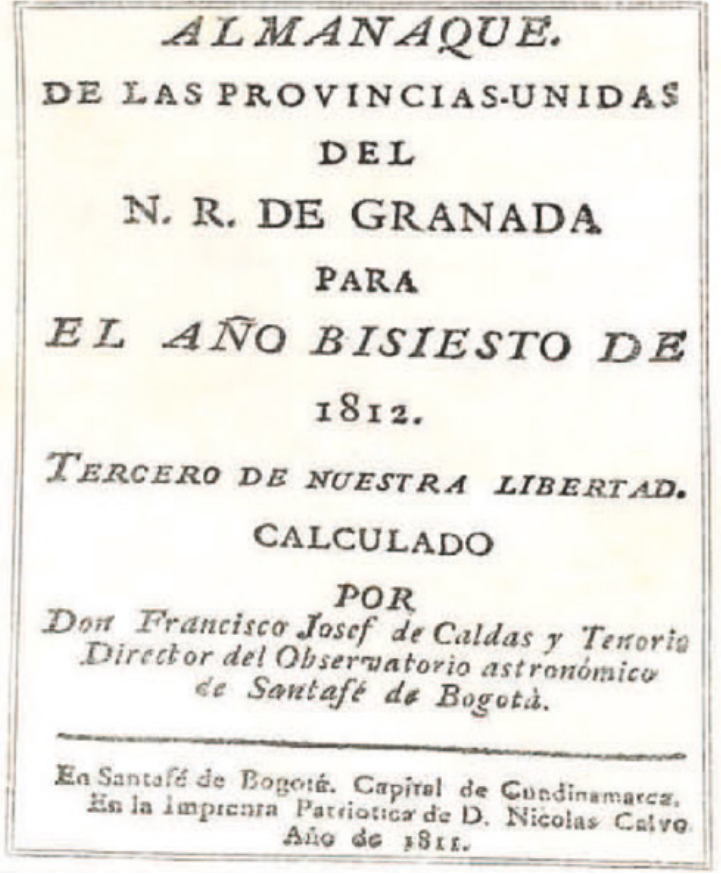

Figura 4. Portada del Almanaque de 1812 (1811). Tomado de: Caldas, Francisco José. "Estudios seleccionados referentes a astronomía, meteorología y física". Revista de la Academia Colombiana de Ciencias Exactas, Físicas y Naturales 1938; 2(5): Inserto.

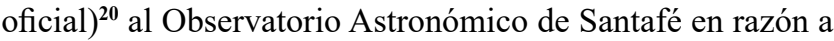
su deterioro en el lugar que fue dispuesto originalmente por los académicos del siglo XVIII, ${ }^{21}$ y del "Artículo necrológico del Sr Dr José Celestino Mutis" escrito por Caldas en los últimos meses de 1808 para dar cuenta de la vida y obra de quien lo había recibido en el seno de la Expedición Botánica desde el año de $1802 .{ }^{22}$

Después de estas entradas de y sobre Caldas en la revista de la ACCEFYN, habría que esperar siete años para que el payanés volviera a ser objeto de una referencia explícita, con ocasión de la sesión solemne de la Sociedad Colombiana de Ingenieros en su honor. ${ }^{23} \mathrm{El}$ autor de este texto fue Jorge Álvarez Lleras, quien tomó para su relación varios extractos de la obra de Caldas a partir de la compilación publicada en 1912 por el historiador Eduardo Posada. ${ }^{24}$ Uno de estos extractos trae una noticia interesante

\footnotetext{
${ }^{20}$ Para una revisión de este episodio, que concluyó con la devolución al Ecuador de la lápida por parte del gobierno colombiano en 1886 en calidad de “donación”, véanse Villacrés Moscoso (1986) y Díaz (1988).

${ }^{21}$ Caldas, [s. f.] 1938; 2(6): 311-313. En: http://dx.doi.org/10.18257/ raccefyn. 742

${ }^{22}$ Caldas, [1808] 1938;2(6):327-328. En: http://dx.doi.org/10.18257/ raccefyn.743

${ }^{23}$ Álvarez Lleras, 1945; 6(22-23): 400-403. En: http://dx.doi. org/10.18257/raccefyn.745

${ }^{24}$ Véase: Posada, Eduardo (comp.). Obras de Caldas. Bogotá: Academia Colombiana de Historia, 1912.
}

sobre una obra "grandiosa" que Caldas habría iniciado en medio de sus viajes en la provincia de Quito entre 1802 y 1805 , la cual se halla, hasta la fecha, desaparecida. A esta se refirió Caldas mismo años después en su angustiosa carta a Pascual Enrile, firmada en octubre 27 de 1816, en los siguientes términos:

Destinado por el Señor Mutis a la provincia de Quito, recorrí estas regiones y colecté un herbario que ascendió a cerca de seis mil ejemplares de plantas ecuatoriales que están depositados en la casa de la Expedición Botánica; este viaje me dio ocasión de comenzar a realizar una obra grandiosa titulada Phitographia ecuatorialis (geografía de las plantas). Este era un corte del globo en el sentido del meridiano, pasando por Quito y abrazando $9^{\circ}$ en latitud, $4,5^{\circ}$ al norte y $4,5^{\circ}$ al sur del ecuador. Esta obra, cuya idea pide un largo detalle, quedó iniciada, y yo tendré el honor de presentar fragmentos a V[uestra] E[xcelencia].

Los volcanes y montes nevados de la Nueva Granada, el nivel de la nieve perpetua, los niveles de los valles y del continente de la Nueva Granada, la altura del mercurio en el mar, y sobre tantos objetos que me sería muy largo enumerar a V[uestra] E[xcelencia], forman otras tantas obras, y cuyos pormenores y planes van a perecer con su autor si V[uestra] $\mathrm{E}$ [xcelencia] no lo socorre. ${ }^{25}$

Un lustro después, a mediados del siglo XX, justamente en 1950, apareció en la revista una reedición de la "Geografía de las plantas" de Alexander von Humboldt, tal y como la había traducido del francés Jorge Tadeo Lozano (1771-1816), y que recuperaría Francisco José de Caldas con el propósito de publicarla en su Semanario del Nuevo Reyno de Granada de $1809 .{ }^{26}$ En aquella ocasión, Caldas había complementado el texto de Humboldt con un "Prefacio", ${ }^{27}$ que fue incluido en la revista de la ACCEFYN en esta misma edición del año que partió en dos el siglo $\mathrm{XX}$, y con una importante serie de "Notas" que no fueron incluidas en la reedición de la ACCEFYN, las cuales se extendieron en su momento prácticamente el mismo número de páginas que el texto original de Humboldt traducido al español. En estas, el payanés buscó aportar al menos 26 precisiones y correcciones explícitas a lo escrito por el prusiano. ${ }^{28}$ Pero este no es este el lugar, ni el momento, de comentar in extenso las coincidencias y disidencias entre Humboldt y Caldas en los albores de la biogeografía; este tema será tratado en una publicación subsecuente en torno a los viajes y observaciones científicas de Caldas. ${ }^{29}$ Para

\footnotetext{
${ }^{25}$ Caldas [1816], citado en: Álvarez Lleras, 1945; 6(22-23): 402.

${ }^{26}$ Humboldt [1803] 1809 en: http://catalogoenlinea.biblioteca nacional.gov.co/client/es_ES/search/asset/132628

${ }^{27}$ Caldas [1809], en Humboldt [1803/1809] 1950; 8(29): 65-103, pp. 65-66. Véase: http://dx.doi.org/10.18257/raccefyn.746

${ }^{28}$ Véase: Caldas $(1809,163-168$-notas 1 a 9-; 169-187 -notas 9 a 26-), en: http://catalogoenlinea.bibliotecanacional.gov.co/client/es ES/search/asset/132629 y http:/catalogoenlinea.bibliotecanacional. gov.co/client/es_ES/search/asset/132630, respectivamente.

${ }^{29}$ Véase: Gómez, Alberto. Caldasiana equatorialis. Viajes y observaciones de Francisco José de Caldas, 1795-1816 (en preparación).
} 
publicaciones preliminares en este dominio se remite al lector a algunas obras más o menos recientes, en las que se definen pormenores de la geografía de las plantas y de la nivelación de las plantas. ${ }^{30}$

En 1951, un año después, la Academia de Ciencias dedicó a Caldas el número 30 del volumen 8 de su revista, con motivo de un nuevo homenaje, al cumplirse 135 años de su fallecimiento (o 180 años de su nacimiento, en función de una fecha hasta ese momento equivocada y citada como 1771) ${ }^{31}$ La razón formal para este homenaje fue referida en las páginas 145 y 146 de la sección editorial con el subtítulo de "Homenaje al sabio Francisco José de Caldas" y en estas se transcribió la noticia de la nueva estampilla que sería emitida en el país para conmemorar "el descubrimiento del hipsómetro" en el año 1799 (Figura 5); ${ }^{32}$ la estampilla había sido solicitada al Presidente de la República por la Academia en una de sus primeras resoluciones institucionales:

Resolución No 7. - La Academia Colombiana de Ciencias Exactas, Físico-Químicas y Naturales, considerando: $1^{\circ}$ - Que el sabio Francisco José de Caldas, partícipe y mártir de nuestra Independencia, realizó estudios e investigaciones relacionadas con el conocimiento de la astronomía, la física y la naturaleza de nuestro suelo; $2^{\circ}$ - Que por sus concepciones sobre la nivelación de las plantas que se cultivan en la vecindad del ecuador puede considerársele como uno de los creadores de las ciencias ecológicas; $3^{\circ}$ - Que su descubrimiento del método de medición de alturas por medio de la ebullición del agua fue una de las más grandes y oportunas contribuciones en orden al conocimiento de la altimetría de las montañas; $4^{\circ}$ - Que tanto por la vida inmaculada del sabio, su permanente amor al estudio y sus investigaciones en las ciencias naturales, su vida es un ejemplo constante para la juventud, y $5^{\circ}$ - Que el descubridor del hipsómetro es desconocido no sólo en el mundo científico

${ }^{30}$ Véase: Díaz-Piedrahita (1997); Castrillón (1997); CañizaresEsguerra (2006); Nieto Olarte (2010); González-Orozco, et al. (2015); Ebach (2015); Gómez-Gutiérrez (2016[a]); Puerta Olaya y Escobar Ortiz (2017); Valencia (2018).

${ }^{31}$ Caldas fue bautizado el 17 de noviembre de 1768 , y se postula que nació el 4 de octubre, día de San Francisco de Asís en el santoral. Su partida de bautismo dice así en su ortografía original: "EI Dr. Dn. Francisco Mosquera y Bonilla Cura Rector de Esta Santa Iglesia Catedral de la ciudad de Popayán. Certifico que en Uno de los Libros Parroquiales, en que se cientan las Partidas de Bautismos, a la F-70 se halla una del tenor siguiente $=$ En dies y siete días del mes de Noviembre, de mil, setecientos, sesenta, y ocho, bautizó el Señor Maestre Escuela Dn. Miguel de Unda, y Luna, puso óleo, y crisma, a Fran[cis]co Joseph, hijo legítimo de Dn. Joseph de Caldas y Dna. Vicenta Tenorio; fueron sus Padrinos Dn. Juan Tenorio, y Dna. Mariana de Arboleda, sus Abuelos, a quienes se les advirtió la obligación, y porque conste lo firmó su Señoría - Dr. Tomas de Eguizaval. Hasta aquí la Partida, que va conforme con el original a que me refiero: y $\mathrm{p}[\mathrm{ar}] \mathrm{a} \mathrm{q}[\mathrm{u}] \mathrm{e}$ conste doy la pres[en]te a pedim[en]to Verbal de Parte, en Popayán, y Febrero Veinte y seis, de mil, ochocientos, y dies anos". Véase Fernández Pérez, Álvaro. "Año y lugar de nacimiento de Francisco José de Caldas". Caldasia, 1955; VII (31): 3-6.

${ }^{32}$ Álvarez Lleras, 1951; 8(30): 145-146. En: http://dx.doi.org/10. 18257/raccefyn.747

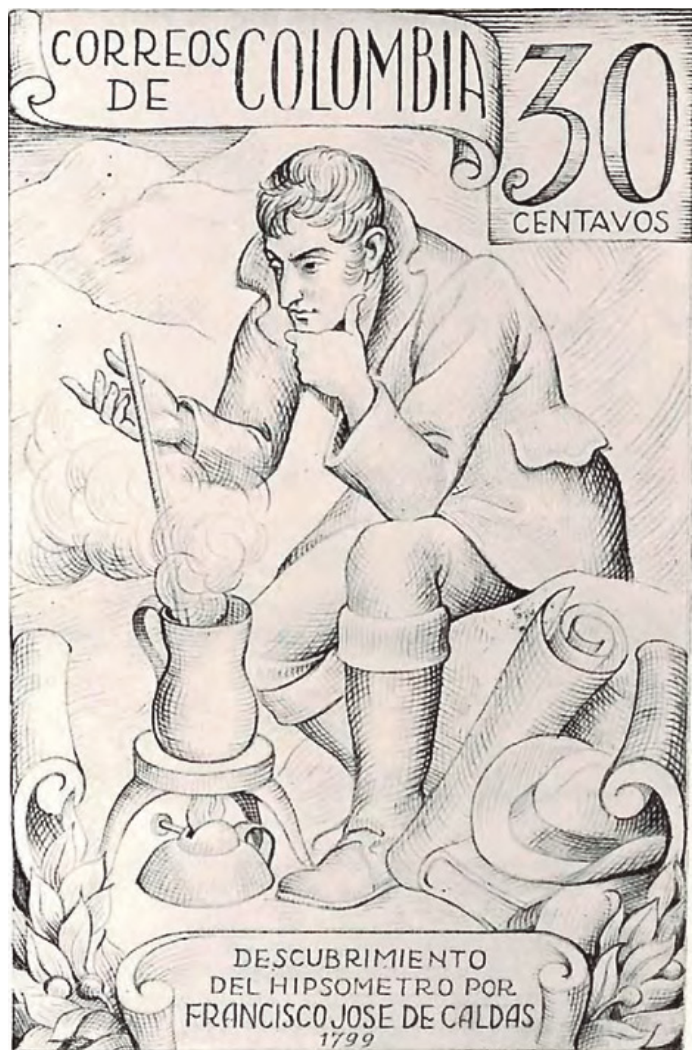

Figura 5. Diseño publicado por la Revista de la Academia Colombiana de Ciencias Exactas, Físicas y Matemáticas para conmemorar el descubrimiento del hipsómetro por Francisco José de Caldas. Autor: Luis Alberto Acuña (1904-1994), 1951.

extranjero sino en su propia patria, RESUELVE: - ARTÍCULO $1^{\circ}$ - Solicitar respetuosamente del Excelentísimo Señor Presidente de la República y del Señor Ministro de Correos y Telégrafos que ordenen una emisión de timbres postales que consagre el descubrimiento del hipsómetro por medio de un dibujo con la imagen del sabio en trance del descubrimiento mencionado y con la siguiente leyenda: "DESCUBRIMIENTO DEL HIPSÓMETRO POR CALDAS, 1799”; ARTÍCULO 2º Remítanse sendas copias de esta Resolución al Excelentísimo Señor Presidente de la República, a los Señores Ministros de Correos y Telégrafos y de Educación Nacional y a la Academia Nacional de Historia. - Comuníquese y cúmplase -. Dada en Bogotá, a 12 de septiembre de 1950. - (Firmado) BELISARIO RUIZ WILCHES, presidente. - ALFREDO D. BATEMAN, secretario. ${ }^{33}$

La solicitud de la Academia de Ciencias fue aceptada con el siguiente decreto emitido solo un mes y trece días después:

MINISTERIO DE CORREOS Y TELÉGRAFOS - Decreto número 003260 de 1950 (octubre 25). - Por el cual se ordena una emisión de estampillas de correos. EL PRESIDENTE DE LA REPÚBLICA DE COLOMBIA en uso de sus facultades legales, y considerando: Que el sabio Francisco José de Caldas, partícipe y mártir de nuestra Independencia, realizó

${ }^{33}$ Ibidem, 145-146. 
estudios e investigaciones relacionadas con el conocimiento de la astronomía, la física y la naturaleza del suelo colombiano, y que en las especies postales deben conmemorarse los hechos históricos, DECRETA: - ARTÍCULO 1ํ- Ordénase la emisión de tres millones (3.000.000) de estampillas de correos de valor facial de treinta centavos $(\$ 0.30)$, las que llevarán la imagen del sabio Caldas y la siguiente leyenda "DESCUBRIMIENTO DEL HIPSÓMETRO POR CALDAS, 1799”. - ARTÍCULO $2^{\circ}$ - Las especies a que se refiere el artículo anterior tendrán valor postal por tiempo indefinido. - Comuníquese y cúmplase -. Dado en Bogotá, a 25 de octubre de 1950. - (Firmado) LAUREANO GÓMEZ. - El Ministro de Hacienda y Crédito Público, (Firmado) RAFAEL DELGADO BARRENECHE. El Ministro de Correos y Telégrafos, (Firmado) JOSÉ TOMÁS ANGULO. ${ }^{34}$

La estampilla correspondiente saldría finalmente emitida en 1958, con un valor de 25 centavos y con un diseño algo diferente al propuesto por la Academia. ${ }^{35}$ En efecto, tanto el retrato y el volcán nevado de Puracé como el hipsómetro de la estampilla de 1958 parecen más ajustados a la realidad que los diseñados en primera instancia por el maestro Acuña (Figura 6).

También en 1951 la revista de la ACCEFYN había incluido un artículo completo titulado "El amor y la sabiduría de Francisco José de Caldas" escrito por el profesor Luis María Murillo Quinche (1896-1974), subsecretario de la Academia, quien había citado a una "reorganización y renuevo" de la corporación frente a los quebrantos de salud de su primer presidente, el profesor Jorge Álvarez Lleras. Esta reunión extraordinaria concluyó con el nombramiento de su sucesor, el también astrónomo y matemático Belisario Ruiz Wilches (1887-1958), quien había sido nombrado por la Universidad Nacional como Director del Observatorio Astronómico Nacional, en ese entonces íntimamente ligado a la Academia.

En ese artículo, que era una transcripción de las palabras que el entomólogo Murillo había pronunciado el 22 de agosto de 1950 con ocasión del 147 aniversario de la fundación del Observatorio, se resume la vida y obra de Caldas en cinco hitos principales: 1- El descubrimiento del hipsómetro (1799); 2- La nivelación de las plantas que se cultivan en la vecindad del ecuador (1803); 3- El Semanario del Nuevo Reino de Granada (1808); 4- El matrimonio Caldas-Barahona (1810); 5- La carta de Caldas a Pascual Enrile unos días antes de su fusilamiento (1816). ${ }^{\mathbf{3 6}}$

\footnotetext{
${ }^{34}$ Ibidem, 146.

${ }^{35}$ En la primera mitad del siglo XX, en los años 1910 y 1947, se habían emitido ya dos estampillas con la efigie de Francisco José de Caldas. La primera, con un valor de 10 centavos, con ocasión del Centenario de la Independencia; la segunda, de 5 centavos, con ocasión del IV Congreso Panamericano de Prensa que había tenido lugar en Bogotá en 1946. Veinte años después, el 12 de octubre de 1966, el Banco de la República reexpediría el billete de veinte pesos oro que venía imprimiéndose desde el año 1927 con un total de cuatro diseños diferentes. Véase Gómez y Amaya (2002, 19 y 22). ${ }^{36}$ Murillo, 1951; 8(30): 149-153. En: http://dx.doi.org/10.18257/ raccefyn. 748
}

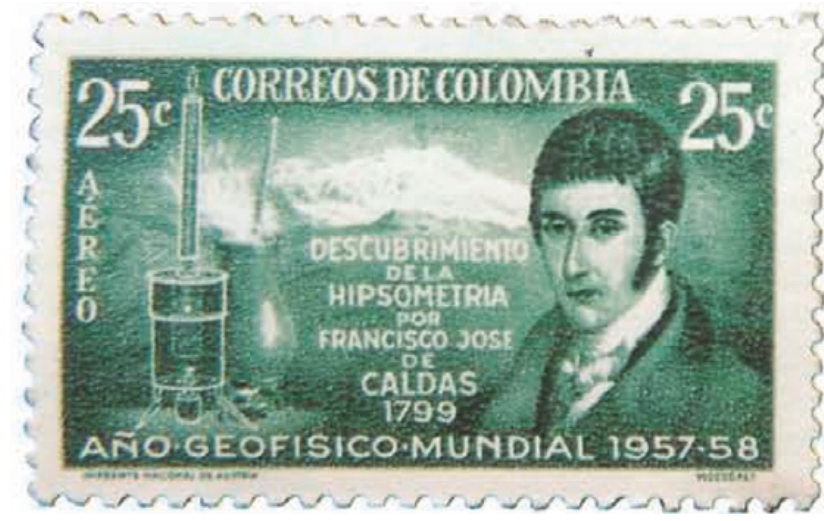

Figura 6. Estampilla conmemorativa del descubrimiento del hipsómetro por Francisco José de Caldas, en el año geofísico mundial (1957-1958). Tomada de: Gómez y Amaya $(2002,30)$.

Una sola ilustración incluyó Murillo con el retrato grabado de Francisco José de Caldas que había elaborado Antonio Rodríguez (c1845-1897) para el Papel Periódico Ilustrado de Alberto Urdaneta (1845-1887) en los años 80 del siglo XIX (Figura 7), a partir del modelo original de Antoine Maurin (1793-1860) publicado en 1849 por Joaquín Acosta (1800-1852) en París, para abrir su reedición de artículos del Semanario de la Nueva Granada y algunos textos suplementarios. El grabado de Rodríguez se publicó en el número 39 del volumen 8 de la revista de la ACCEFYN, con un velo de papel traslúcido que tenía impresos dos párrafos en letra carmelita con la descripción física y psíquica que hizo Lino de Pombo de su maestro, a quien había conocido bien en vida:

Era Caldas de estatura regular y complexión robusta; su color moreno, el rostro redondo, la frente espaciosa, los ojos negros, algo melancólicos, el pelo negro y lacio, el cuello corto, su andar desembarazado, pero lento y contemplativo. Vestía de ordinario una levita o sobretodo de paño oscuro, que abrochaba y desabrochaba sin cesar cambiando de solapa, de manera que duraban muy poco los botones; y no dejaba de la mano un bastoncito flexible, ni de la boca un pedacito de tabaco fino torcido. Era aseado, pero no pulcro en el traje; de modales suaves, trato afable y conversación amena.

$\mathrm{Su}$ carácter franco, su índole pacífica. Ni las riquezas, ni ambición de ninguna especie tenían para él atractivo; y fuera de la pasión por sus favoritos estudios, no ejercía imperio sobre él otra alguna. Era católico creyente, y de las más puras costumbres. Era filósofo, en la genuina acepción de esta palabra. Su matrimonio lo contrajo en 1810 , recomendando a varios de sus amigos de Popayán que le buscasen mujer digna de sus prendas de ser la esposa de un hombre honrado: y uno de ellos, el señor Agustín Barahona, le propuso a su sobrina la señora María Manuela Barahona, describiéndosela fiel y circunstanciadamente, y obtuvo de ella el consentimiento cuando la hubo aceptado Caldas. ${ }^{37}$

\footnotetext{
${ }^{37}$ Pombo, [1852] 1951; 8(30): inserto. En: http://www.accefyn. com/revista/Vol_8/no_30/El_amor_sabiduria.pdf
} 

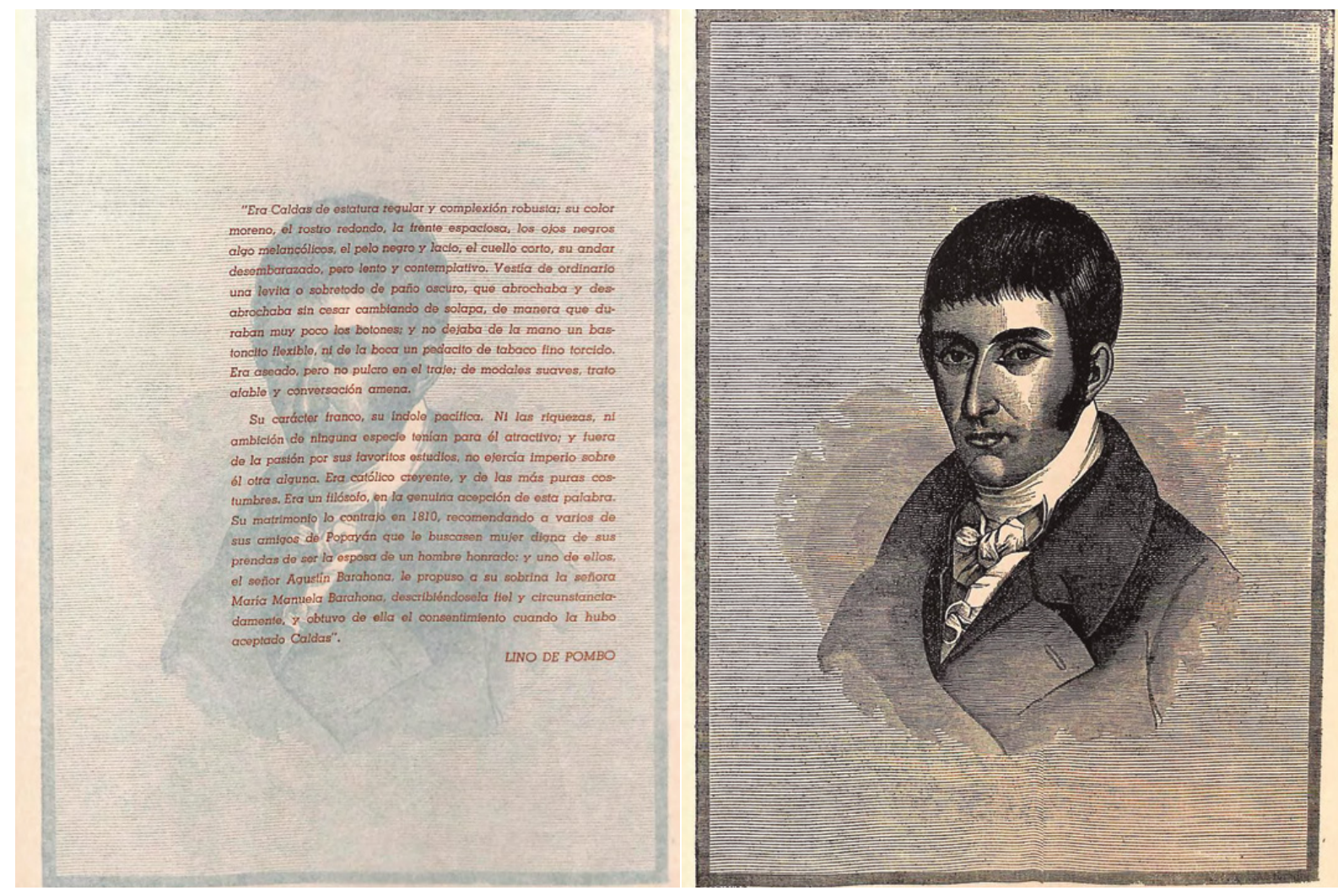

Figura 7. Francisco José de Caldas. Grabado de Antonio Rodríguez (c1845-1897) para el Papel Periódico Ilustrado de Alberto Urdaneta (1845-1887) en 1883

Un año después, la Revista de la Academia Colombiana de Ciencias Exactas, Físicas y Naturales volvió sobre los terrenos más exactos, físicos y naturales de Caldas, al incluir un artículo escrito por Alfredo D. Bateman Quijano (19091988) sobre el hipsómetro del payanés. En este, Bateman, formado en la Universidad Nacional en donde fue Decano y Profesor Emérito de la Facultad de Ingeniería, presentó la primera aproximación matemática al método hipsométrico caldasiano que juzgó inexacto y sobre el que se pronunció con las siguientes conclusiones:

a Caldas fue el primero en señalar que existe una relación entre la temperatura de ebullición del agua y la altura barométrica, en un mismo lugar;

b Fue igualmente el primero en hallar una ecuación que ligara estos dos valores;

c Si bien la fórmula de Caldas no es exacta, sí tiene el mérito de la originalidad;

d Los físicos que estudiaron posteriormente este fenómeno lo estudiaron indirectamente, pues partieron del principio físico de la tensión del vapor de agua;

e Por tanto, ante la historia de la física, Caldas debe ser considerado, sin lugar a duda, como el verdadero inventor de la hipsometría. ${ }^{38}$

\footnotetext{
${ }^{38}$ Bateman, 1952; 8(32): 449-457. En: http://dx.doi.org/10.18257/ raccefyn. 749
}

En 1959, al conmemorarse el centenario de la muerte de Alexander von Humboldt, Alfredo Bateman y Enrique Pérez Arbeláez (1886-1972), se refirieron en sendos artículos al vínculo a la vez virtuoso y problemático del prusiano y el payanés bajo los títulos de "Caldas y Humboldt" (Bateman) ${ }^{39}$ y de "La ciencia y la historia" (Pérez-Arbeláez), ${ }^{40}$ el segundo con dos subtítulos sugestivos: "El caso Caldas-Humboldt" y "No hubo tal adonis". En ambos casos, en el artículo de Bateman -con una aproximación pormenorizada paso a paso del encuentro-, y en el de Pérez Arbeláez -con una exploración del carácter eventualmente bipolar del payanés-, se buscó aclarar lo que Jorge Arias de Greiff referiría en su momento como una transición "de la cima a la sima" en la relación personal de los dos naturalistas. ${ }^{41}$

En 1960, el director en funciones de la revista de la ACCEFYN, profesor Luis María Murillo, incluyó en la sección editorial de la revista del mes de agosto las palabras que había pronunciado en el Observatorio Astronómico para celebrar a la vez el sesquicentenario de la Independencia Nacional y los 157 años de la fundación del edificio en el

\footnotetext{
${ }^{39}$ Bateman, 1959; 10 (41): LX-LXVII. En: http://dx.doi.org/10.18257/ raccefyn. 750

${ }^{40}$ Pérez Arbeláez, 1959; 10 (41): LXX-LXXII. En: http://dx.doi. org/10.18257/raccefyn.751

${ }^{41}$ Véase: Arias de Greiff, 1994, 43.
} 
que se reunió la Academia de Ciencias en sesión conjunta con las Academias de Historia y de Geografía. Ese texto, de tono exegético, tal y como lo calificó el propio autor, fue dividido en "cuatro estaciones" que se revelarían al final de su discurso como ferroviarias, y no planetarias como correspondía al aparato científico al que los asistentes estaban integrados.

Las cuatro estaciones fueron subtituladas como: 1Caldas y la cuna de la emancipación; 2- Caldas y las bases científicas del federalismo de la Nueva Granada; 3- Caldas y las organizaciones de sectores regionales que ahora se proyectan; 4- Y sucedió que... Caldas tenía razón. ${ }^{42}$

Aunque las tres primeras paradas del tren metafórico del profesor Murillo se entienden bien como una aproximación a la dimensión política y social de la obra del payanés, la cuarta, aparentemente descarrilada, fue justificada por el autor como un ejercicio de defensa corporativa de última hora frente al ataque ético y filosófico, "grato al paladar de un intelectual", que Murillo conoció en esos días pero que el historiador bogotano Bernardo J. Caycedo Acosta (1894-1982) había publicado algunos años atrás bajo el título Grandezas y miserias de dos victorias (1951). En su obra, Caycedo perfiló a Caldas como el principal instigador de la lucha entre centralistas y federalistas en 1813, cuando los ejércitos comandados por Antonio Baraya (1776-1816) y Antonio Nariño (1765-1823) se enfrentaron en dos ocasiones -primero en Ventaquemada y luego en la plaza de San Victorino en Santafé- en una partida que quedó empatada uno a uno, pero que dio la victoria final a Nariño, a quien Caldas calificó en su correspondencia -después de su paso al campo federalista- como "el tirano".

La figura literaria que el historiador Caycedo utiliza como leit-motiv para apuntalar su teoría política sobre el paradójico Caldas, a quien describe como la eminencia gris de lo que algunos han llamado la Patria Boba y otros la Primera República, fue tomada del retrato escrito que Lino de Pombo hizo de su maestro, quien, decía el pupilo, "abrochaba y desabrochaba sin cesar [su levita de paño oscuro] cambiando de solapa, de manera que duraban muy poco los botones". ${ }^{43}$

Sigue a este artículo editorial un extracto del texto que el geógrafo Pablo Vila i Dinarès (1881-1980) había publicado en marzo de ese mismo año en la Revista Shell de Venezuela, titulado "Caldas y los orígenes eurocriollos de la geobotánica", ${ }^{44}$ con el que fundamentaba la sincronía de la formulación teórica de la biogeografía en Caldas y en Humboldt, bajo los descriptores de "fitografía" o "nivelación de las plantas" en el payanés, y "geografía de las plantas" en el prusiano.

\footnotetext{
${ }^{42}$ Murillo, 1960; 11(42): VII-XV. En: http://dx.doi.org/10.18257/ raccefyn. 752

${ }^{43}$ Pombo ([1852] 1951, inserto).

${ }^{44}$ Vila, 1960; 11(42): XVI-XX. En: http://dx.doi.org/10.18257/ raccefyn. 753
}

El texto del profesor Vila sigue siendo consultado y referenciado por científicos e historiadores, ${ }^{45}$ por cuanto es una pieza particularmente bien estructurada y ponderada que, evitando el tono hagiográfico y exegético que fue usual en el siglo XX, y haciendo justicia al título de su artículo, explica bien los orígenes a la vez europeos y criollos de la geobotánica o biogeografía.

Partiendo de antecedentes europeos como los trabajos del naturalista y geólogo suizo Horace-Bénédict de Saussure (1740-1799) en la vegetación del Mont Blanc alpino, y los trabajos del geólogo y botánico francés Louis Ramond, barón de Carbonnières (1755-1827) sobre la distribución de las plantas en el Monte Perdido pirenéico, Vila explica que Alexander von Humboldt buscó reproducir esos mismos conceptos sobre las variaciones fenotípicas (y taxonómicas) de la vegetación en función de la altitud, pero "en las cercanías del ecuador".

Y aquí entra Caldas a figurar. Dice Vila que, al comentarle al prusiano sobre su método hipsométrico -sin considerar por el momento qué tan acertado fuera este desde el punto de vista físico y matemático-, "el Barón debió darse cuenta de que aquel criollo se hallaba en el camino de establecer las relaciones existentes entre las plantas, [la] temperatura, y la altitud, lo cual no dejó de sorprenderle". "Ambos", opina Vila, "se encontraron en la vía de los mismos estudios geobotánicos". Y se encontraron en un silencio explícito: ambos en silencio en medio de tanta elocuencia. Un silencio, pues, elocuente.

Lo realmente paradójico, tal y como lo precisa Vila, es que Humboldt escribió el 25 de noviembre del año 1802, desde Lima, al astrónomo y matemático francés Jean-Baptiste Joseph Delambre (1749-1822) -y no a un botánico-, es decir solo seis meses después de haberse despedido y trabajado con Caldas en Quito, una carta en la que le cuenta de "Mutis, [del] presidente de la [Audiencia de Quito, de] los Montúfar, [y] nada de Caldas", a pesar de que le expone que "no hay vegetal del cual no podamos indicar la roca que habita y la altura en toesas hasta la cual se eleva; a tal punto que la geografía de las plantas tendrá en nuestros manuscritos datos muy exactos", tema que podía haber comentado con Caldas en esos días (además de Bonpland, a quien cosa curiosa- nunca se ha asociado con este hallazgo), por cuanto el payanés se había interesado evidentemente en la botánica, al lado de Bonpland, y en las altimetrías, al lado de Humboldt.

De hecho, y este es asunto que también comenta Vila, no solo envió Humboldt a Mutis en cuanto pudo su primer borrador del "Ensayo sobre la geografía de las plantas", sino que lo hizo desde Guayaquil a través del padre de Carlos Montúfar y de Caldas en Quito, nuevamente sin mencionar

\footnotetext{
${ }^{45}$ Véase, por ejemplo, Díaz-Piedrahita (1997); Cañizares-Esguerra (2006); Nieto Olarte (2010); González-Orozco, et al. (2015); Ebach (2015); Gómez-Gutiérrez (2016[a]); Puerta Olaya y Escobar Ortiz (2017); Valencia (2018).
} 
al payanés de manera explícita, y también dedicándoselo muy especialmente al gaditano. Finalmente, arguye Vila, Humboldt publicaría la primera versión impresa de su Essai sur la géographie des plantes (1805/1807) en París, de manera algo apresurada en comparación con los 29 volúmenes restantes de su viaje americano, con una traducción prácticamente inmediata al alemán bajo el título de Ideen zu eine Geographie der Pflanzen (1807).

La primera de estas publicaciones, en francés, fue dedicada a Joseph de Jussieu (1704-1779) y René Desfontaines (1750-1833), reputados botánicos del Jardin des Plantes de París, y la segunda, en alemán, a Johann Wolfgang von Goethe (1749-1832), su contertulio de Jena en 1797. Mutis y Caldas, que quedaron atrás, en América, desaparecen del panorama; y desaparecen también de los créditos. ${ }^{\mathbf{4 6}}$

El historiador Mauricio Nieto, en un coloquio reciente sobre el encuentro Humboldt-Caldas en el dominio de la teoría biogeográfica, comentó que debe mirarse con reserva cualquier elaboración sobre la "prioridad científica", puesto que esta rara vez surge aislada en la mente de un solo individuo, y es usualmente producto de una comunidad ilustrada. Siguiendo esta recomendación, se podría proponer una alternativa para la controversia HumboldtCaldas, tanto como para otros casos similares en la historia de las ciencias que permanecen enredados en una discusión sin fin de eventuales prioridades: la de considerar los determinantes de estas simultaneidades, de estas sincronías. ¿Cómo, en dónde y por qué se encontraron dos individuos tan disímiles en lo que llamó Vila: "la vía de los mismos estudios geobotánicos"?

En una revisión comentada del presente texto, el historiador José Antonio Amaya abre otra opción alterna al considerar que esta coincidencia se podría interpretar también como la articulación "de un discurso previo e inconsciente $[. .$.$] con contribuciones posteriores, formando$ parentescos de conocimiento a partir de problemas que se despliegan en [el curso del tiempo]". ${ }^{47}$

Pero volvamos a 1960. En aquel año se publicó un texto adicional en la Revista de la Academia Colombiana de Ciencias Exactas, Físicas y Naturales, esta vez escrito por dos reconocidos miembros de la Academia Colombiana de Historia, Luis Martínez Delgado (1894-1973) y Sergio Elías Ortiz (1894-1978), bajo el título "Francisco José de Caldas, periodista" ${ }^{48}$ En este, los historiadores Martínez y Ortiz presentan los antecedentes coloniales del periodismo en la Nueva Granada (El Aviso del Terremoto

\footnotetext{
${ }^{46}$ Para una revisión de la razón de ser de estas dedicatorias, tanto como una interpretación más detallada de la secuencia de hechos relativa a la publicación de la geografía de las plantas de Humboldt y de la nivelación de las plantas de Caldas, véase Gómez-Gutiérrez (2016[a]).

${ }^{47}$ Amaya (comunicación personal).

${ }^{48}$ Martínez Delgado y Ortiz, 1960; 11(42): XXXI-XXXVI. En: http://dx.doi.org/10.18257/raccefyn. 754
}

y la Gaceta de Santafé de Bogotá -1785-, el Papel Periódico de la Ciudad de Santafé de Bogotá -1791 a 1797-, el Correo Curioso, Erudito, Económico y Mercantil de Santafé de Bogotá -1801-, El Redactor Americano -1806 a 1808-y el Semanario del Nuevo Reino de Granada -1808 a 1811-), las razones que hicieron necesario un nuevo Diario Político de Santafé de Bogotá tras la firma del Acta de la Independencia del 20 de julio 1810, y cómo esta función recayó en Francisco José de Caldas en razón a su experiencia de publicista científico y social en el más reciente seriado periódico colonial, el Semanario del Nuevo Reino de Granada, fundado apenas dos años atrás, en 1808 , y todavía en circulación en esos días.

Caldas se había asociado con José Joaquín Camacho y Rodríguez de Lago (1766-1816) para solicitar a la nueva Junta Suprema de Gobierno que se les permitiese "la impresión de un papel público [...] con el objeto de presentar al reino los derechos de sus pueblos conciliándolos con el decoro de la soberanía que los representa". La respuesta fue positiva, disponiendo la suma de "dos mil pesos [...], la cual [debían reintegrar] de los productos de su impresión, dentro del preciso término de seis meses que proponen los redactores, a la real hacienda, de cuyos fondos se ha de verificar el suplemento". Caldas y Camacho habían obtenido así a la vez el permiso y la plata para llevar a cabo su iniciativa. El editorial del primer número de este novedoso Diario Político impreso el 27 de agosto de 1810 -apenas 37 días después de la revuelta del florero de José González Llorente- hizo explícita su intención:

Hagamos ver a esa Europa orgullosa, que tenemos virtudes y que somos dignos de formar una nación libre; hagámosle ver que podemos resistir a sus escuadras, a sus ejércitos y a su cañón, con nuestra reunión pacífica y fraternal; desde Cúcuta hasta Loja, desde las llanuras del Orinoco hasta el Chocó, no se oiga sino una voz, y que no haya sino unos mismos sentimientos. Libertad, independencia, subordinación a las autoridades, patriotismo, humanidad. He aquí nuestro código y el único que nos puede salvar en esta crisis política. ${ }^{49}$

Aunque el Diario Politico de Santafé de Bogotá produjo en el curso de cinco meses, entre agosto y diciembre de 1810 , un total de 45 entregas correspondientes a "15.000 números y una cantidad de impresos", en la edición número 46 de enero $1^{\circ}$ de 1811 , los editores hubieron de confesar que, en razón a la carestía del papel, no podrían devolver el dinero pactado y anunciaron al público "la necesidad en que [se hallaban] de suspender la publicación”.

El efecto social de esta publicación en momento tan crítico del nacimiento de la república está por analizarse en profundidad, aunque está claro que fue un factor de oposición a la monarquía determinante por cuanto los "pacificadores" que intentaron restaurarla, entre $1815 \mathrm{y}$ 1819, registraron en lo que los historiadores Martínez Delgado y Ortiz llamaron la "ficha de inmortalidad" de uno de los editores, el siguiente párrafo:

\footnotetext{
${ }^{49}$ Ibidem, 35
} 
Joaquín Camacho. - Fue diputado del Congreso rebelde, acérrimo en seguir la independencia y hombre perverso. Escribió varios papeles y periódicos con máximas contrarias a la causa del Rey nuestro Señor, y a la dignidad de la Nación Española. ${ }^{50}$

En el caso de Caldas, su "ficha de inmortalidad" fue más breve:

Francisco Josef de Caldas. - Ingeniero General del Exército rebelde y General de Brigada. ${ }^{51}$

Con eso los fusilaron.

Los académicos historiadores Martínez Delgado y Ortiz habían erigido a Caldas a la estatura de periodista político como consecuencia de su asociación con Camacho y de su rigor continuado por espacio de más de tres años en el Semanario del Nuevo Reino de Granada, semanario calificado por ellos mismos como "la primera revista verdaderamente científica de este continente". Como lo postuló Mauricio Nieto en varias de sus obras, Caldas llegó a representar bien en su tiempo la dimensión a la vez científica y política de la ciencia en el Nuevo Reino de Granada. ${ }^{52}$

Después de esta dramática historia sobre el final inesperado de un científico en medio de un intento de restauración monárquica, ${ }^{53}$ habría que esperar más de 30 años, hasta ingresar en la década de los noventa en el siglo XX, para encontrar un nuevo artículo sobre Caldas en la revista de la Academia de Ciencias. En efecto, en 1992, el botánico Santiago Díaz-Piedrahita (1944-2014) publicó su elaboración sobre "Francisco José de Caldas y la botánica", con una "síntesis crítica de la actividad adelantada durante cerca de 10 años [...] por el sur de Colombia y por territorio ecuatoriano entre 1802 y $1805 " .54$ Inicia el profesor Díaz-Piedrahita esta síntesis con una relación sobre la formación botánica de Caldas a partir de 1801 gracias a su vínculo epistolar con José Celestino Mutis (1732-1808) y a su encuentro personal con Aimé Bonpland (1773-1858) y Alexander von Humboldt (1769-1859), seguida por una descripción de sus labores botánicas en Quito y alrededores, ilustrándolas con una lámina clave que representa la vista occidental del volcán Imbabura con la "nivelación de 30 especies de plantas", cada una de ellas recolectada e identificada por Caldas (Figura 8). Los componentes de este dibujo fueron registrados por el payanés a partir de septiembre de 1802, seis meses antes de conocer el esquema que Humboldt enviaría a Mutis en febrero de 1803, con base en el cual el prusiano expondría en Europa a partir de 1805 su "geografía de las plantas", concepto fundacional de la biogeografía.

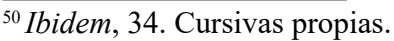

${ }^{51}$ Ibidem, 34.

${ }^{52}$ Véase: Nieto Olarte (2007).

${ }^{53}$ Para profundizar en este periodo de la historia de Colombia véase Gutiérrez Ardila. Daniel. La restauración en la Nueva Granada (1815-1819). Bogotá: Universidad Externado de Colombia, 2016.

${ }^{54}$ Díaz-Piedrahita, 1992; 18(70): 369-382. En:

http://dx.doi.org/10.18257/raccefyn.755
}

Con todo esto dispuesto, Díaz-Piedrahita pasó al núcleo de su reflexión sobre la calidad de botánico que fue Caldas, con una discusión sobre los conceptos biogeográficos y ecológicos que el payanés propuso y afinó en el curso de los años como lo demuestran bien sus manuscritos, los cuales quedaron, en su mayoría, inéditos en vida del payanés en razón a su muy sufrido aislamiento de la corriente intelectual europea. El artículo del botánico Díaz-Piedrahita trae cuatro imágenes adicionales que ilustran: a) la Baccharis genistelloides que Caldas denominó Molina con el número 146 en su propia serie de recolecciones, el cual se conserva en el Herbario del Instituto de Ciencias de la Universidad Nacional de Colombia en Bogotá; b) fragmentos de manuscritos de la Cinchografía; c) el título manuscrito por Caldas del cuadernillo con sus propios "Diseños de plantas", y d) un ejemplo de estos diseños correspondiente a Aethanthus dichotomus, cuyo original policromo se conserva en los archivos del Real Jardín Botánico de Madrid.

En 1996, el profesor Jorge Arias de Greiff, en ese entonces director del Observatorio Astronómico Nacional, quiso volver sobre "El método de Caldas para medir la elevación de las montañas", a pesar de que, como el mismo lo dijo en su introducción, sobre este método "es mucho lo que se ha escrito. Sin embargo, aún pueden ser útiles algunos comentarios y aclaraciones adicionales".55 Esta profundización, característica de un científico riguroso, permitió a Arias de Greiff y a sus lectores entender los fundamentos matemáticos necesarios para explicar las diferencias entre la hipsometría meridional americana y la hipsometría septentrional europea, y cómo estas diferencias -más allá de las variables y condicionantes éticas (vistas por algunos historiadores como eventualmente antiéticas) de Humboldt en su relación con Caldas y otros naturalistas tan creativos como él mismo- pueden sustentar la originalidad $\mathrm{y}$ prioridad del método hipsométrico caldasiano frente a métodos semejantes, pero no iguales, de medición de los grados termométricos de ebullición del agua en diferentes alturas sobre las montañas, como el de Saussure, o como el del propio Humboldt. ${ }^{\mathbf{5 6}}$

Veinte años después de esta reflexión, en el bicentenario de la muerte de Caldas, se optó por dedicar al payanés tres portadas sucesivas en la revista de la Academia de Ciencias,

\footnotetext{
${ }^{55}$ Arias de Greiff, 1996; 20(76): 63-69. En: http://dx.doi.org/10.18257/ raccefyn. 756

${ }^{56}$ Para elaboraciones complementarias sobre la hipsometría de Caldas, véanse los textos de Arboleda, Albis González y MartínezChavanz, y del propio Jorge Arias de Greiff (en una reelaboración de su primera aproximación en 1996), en la compilación de Valencia (2016). El profesor Arboleda precisó, al comentar el presente artículo con el autor, que debe atenderse al hecho de que "la interpretación histórica de prioridad entre Caldas y Humboldt [tal como ha sido postulada por varios académicos críticos, incluido él mismo, contrasta] con el punto de vista hagiográfico, no exento de cierto espíritu de partido, que desafortunadamente ha prevalecido [en este punto] en nuestra historiografía".
} 


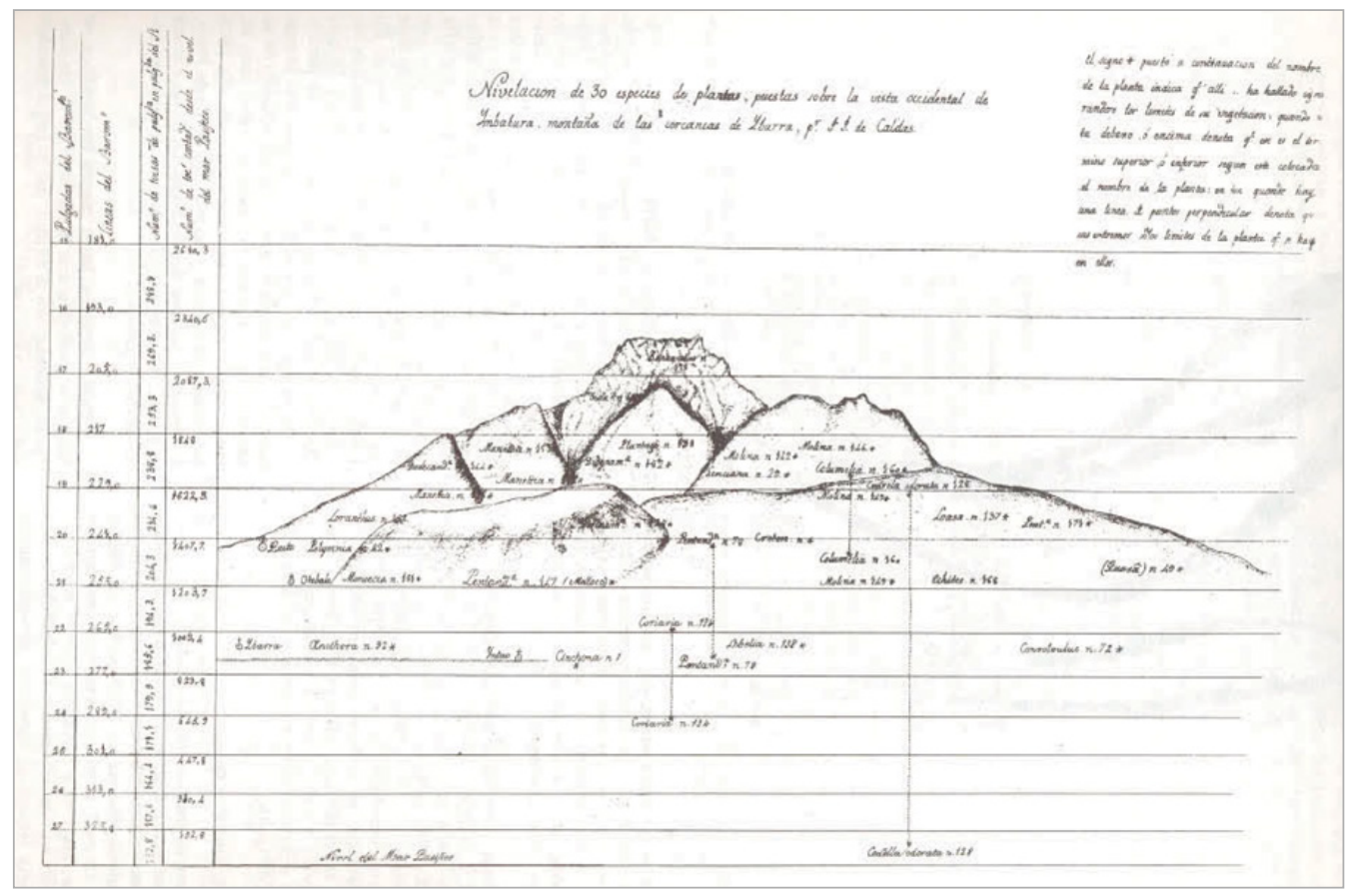

Figura 8. Mapa del flanco occidental del volcán Imbabura en las cercanías de Ibarra, con la nivelación de 30 especies de plantas.

alusivas todas ellas a su obra. Así lo expresó el académico y matemático Luis Carlos Arboleda en el primer editorial del año 2016:

Con motivo de conmemorarse en el próximo mes de octubre el bicentenario de la muerte de Francisco José de Caldas (17681816), la Academia Colombiana de Ciencias Exactas, Físicas y Naturales ha venido adelantando desde el año pasado, en conjunto con universidades, bibliotecas, museos y otras instituciones académicas y científicas, distintas actividades tendientes a recordar aspectos de la vida y la obra del personaje histórico que sin duda alguna más contribuyó a la promoción de la cultura científica en los primeros momentos de instauración de nuestra República. A estas actividades se suma ahora la Revista de la Academia Colombiana de Ciencias Exactas Físicas y Naturales al dedicar a la figura de Caldas el diseño de las portadas de los [tres primeros] números publicados en el volumen 40 de este año. ${ }^{57}$

Pero no solo introdujo protocolariamente Arboleda ese año conmemorativo en la revista, también presentó sus consideraciones disciplinares en calidad de coordinador del Grupo de Historia y Filosofía de la Ciencia de la Academia, bajo el título "Caldas, matematización de la naturaleza y sentimiento telúrico". En este texto, Arboleda trató sobre la validación humboldtiana de Caldas como hombre de ciencia con dos referencias literales, la primera de ellas indirecta, puesto que fue copiada y traducida por Caldas a partir de los diarios manuscritos del prusiano. Humboldt, de acuerdo con el payanés, lo había descrito para sí mismo en los siguientes términos:

${ }^{57}$ Arboleda, 2016, 40(154): 6-7. En: http://dx.doi.org/10.18257/ raccefyn. 356
Este Caldas es un prodigio en astronomía. Nacido en las tinieblas de Popayán y sin haber ido nunca más allá de Santafé, ha construido barómetros, un sector, un cuarto de ciclo en madera. Mide meridianos y latitudes mediante gnomones de 12 a 15 pies. ¡Qué no habría hecho este joven hombre en un país con más medios, en donde no hay que aprender todo por sí mismo! Las obras de Bouguer y de La Condamine han tenido una influencia singular sobre los americanos de Quito a Popayán. El territorio (sol) de este país ha llegado a ser clásico y podría decirse que esto tiene que ver con una característica telúrica (sol natal). ${ }^{58}$

La segunda referencia explícita que trae Arboleda para fundamentar la validación humboldtiana del científico neogranadino había sido referida por Alfredo Bateman a partir del diario del prusiano:

El señor Caldas, de quien no se elogiará bastante el celo por el progreso de la geografía [...] observó la latitud de Gigante con instrumentos construidos por él mismo, a saber, un cuarto de círculo de 16 pulgadas, y un gnomon de cinco pies... Para fijar la longitud, el señor Caldas observó con cuidado extremo, el eclipse de luna del 3 de diciembre de 1797, se sirvió para esto de un anteojo acromático de treinta pulgadas y de un buen reloj. ${ }^{59}$

Arboleda cierra su reflexión editorial aportando la evidencia de la autodefinición a la vez filosófica y pragmática de Caldas como individuo "útil en la ciencia y con la ciencia al doble proyecto social de la élite criolla [en el] año I de la independencia de la Nueva Granada":

\footnotetext{
${ }^{58}$ Humboldt, [1801] 1992, s.p. Citado en Ibidem.

${ }^{59}$ Humboldt, 1801. Citado en Ibidem.
} 
Observar el cielo por observarlo sería una ocupación honesta, pero no pasaría de ser una curiosidad estéril que llenase los momentos del hombre ocioso y acomodado. Este observador sería inútil, y la Patria lo miraría como un consumidor de quien no esperaba nada. Nosotros no queremos representar este papel en la sociedad: queremos que nuestros trabajos astronómicos mejoren nuestra geografía, nuestros caminos y nuestro comercio. ${ }^{60}$

La portada conmemorativa que abrió este volumen 40 de la Revista de la Academia Colombiana de Ciencias Exactas, Físicas y Naturales, en su número 154, correspondió a una imagen cartográfica de las "Provincias Unidas de la Nueva Granada. De orden del Gobierno General por el Con. Francisco José de Caldas, Coronel del Cuerpo Nacional de Ingenieros" "F1 (Figura 9), una lámina que hace parte de un mapa general de las Provincias Unidas de la Nueva Granada en 1815, en particular de la Ciénaga de Santa Marta y el territorio circundante a esta. La fuente de donde fue tomada esta ilustración ${ }^{62}$ da una idea de la importancia de la cartografía en los tiempos de la primera República en la Nueva Granada.

La siguiente portada, en el número 155 (Figura 10), traía una serie de mariposas conservadas en un insectario a las que Jorge Reynolds Pombo, emparentado por su línea materna con el sabio Caldas, se refirió como "Las mariposas de Francisco José de Caldas". El académico y entomólogo Gonzalo Andrade Correa describió así el hallazgo: "En las cajas de insectos de Caldas, encontramos mariposas, cucarrones, libélulas, polillas, abejas y avispas, las que se calcula llevaban más o menos unos doscientos años sin que tales cajas se abrieran por primera vez. Esto lo comprobamos porque en la base de las cajas no había más agujeros producto de los alfileres que tenían los ejemplares para sujetarlos". Y a continuación precisa lo que decía la tradición la familia Pombo, según se la refirió Reynolds: "Me acuerdo que en mi casa durante toda la vida desde que yo estaba muy pequeño, ahí estaban los dos marcos, cuando las miraba mi mamá me decía: Estas cajas vienen por herencia del sabio Caldas, fue una colección que él hizo. ${ }^{63}$ Las mariposas están siendo analizadas por Andrade Correa, y hasta el momento no se ha encontrado ningún indicio que contradiga el hecho de que ese insectario hubiera podido pertenecer a Caldas. Tampoco una confirmación.

La tercera portada del año en el que se recordó en la revista de la ACCEFYN el bicentenario del fusilamiento de Caldas trajo la imagen de la primera página de un manuscrito caldasiano inédito (no póstumo) hallado en una librería de antigüedades en París, y repatriado por la Pontificia Universidad Javeriana a Bogotá en ese mismo año de 2016

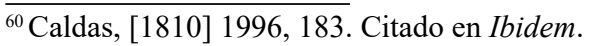

${ }^{61}$ Caldas, [1815]. En: http://www.colombiaaprende.edu.co/html/ mediateca/1607/article-239570.html; 125.

${ }^{62}$ Nieto Olarte, 2006

${ }^{63}$ Andrade, 2016; 40(155): 190-191. En: http://dx.doi.org/10.18257/ raccefyn. 389
}

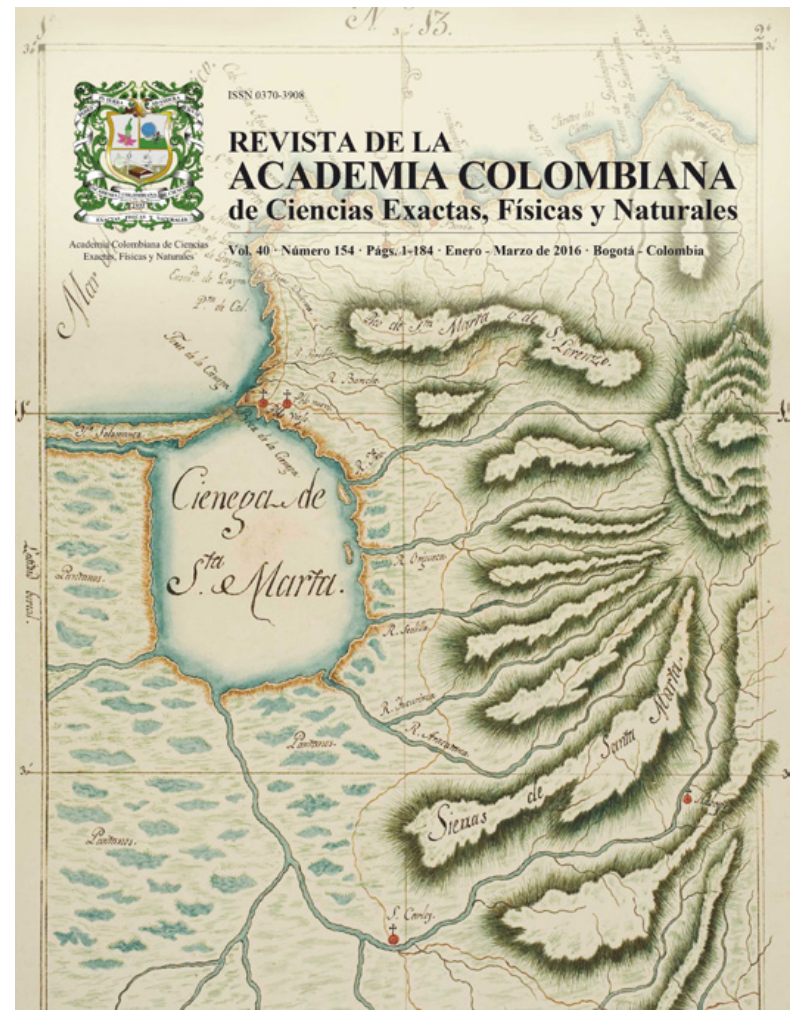

Figura 9. Portada Revista Academia Colombiana de Ciencias Exactas Físicas y Naturales 40(154). Enero-Marzo 2016.

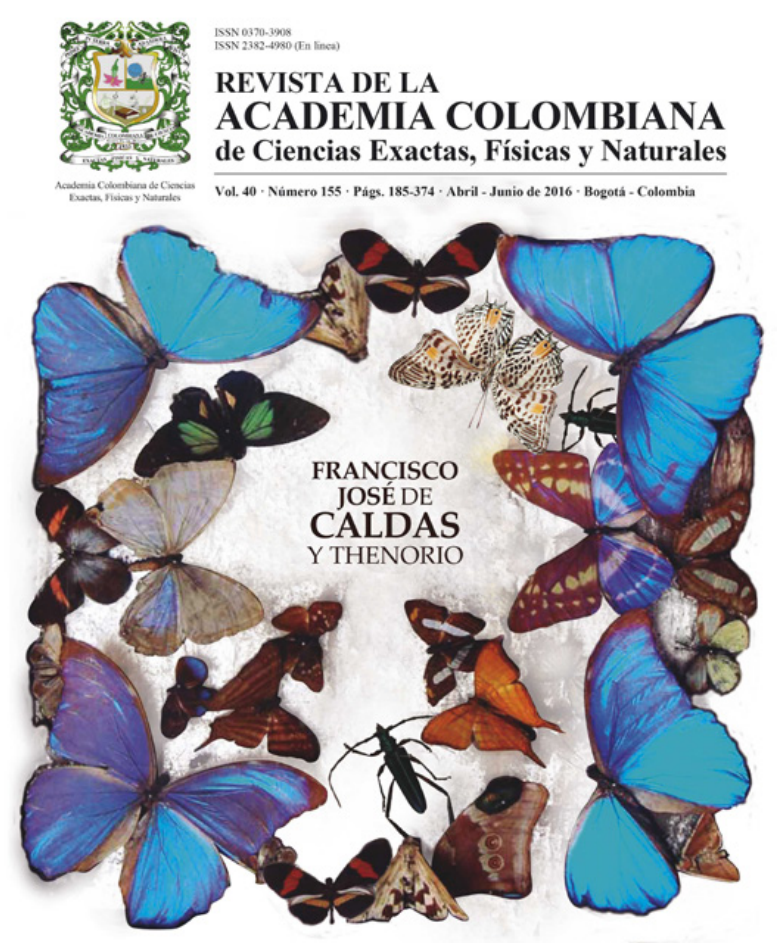

Figura 10. Portada Revista Academia Colombiana de Ciencias Exactas Físicas y Naturales 40(155). Abril-Junio 2016. 


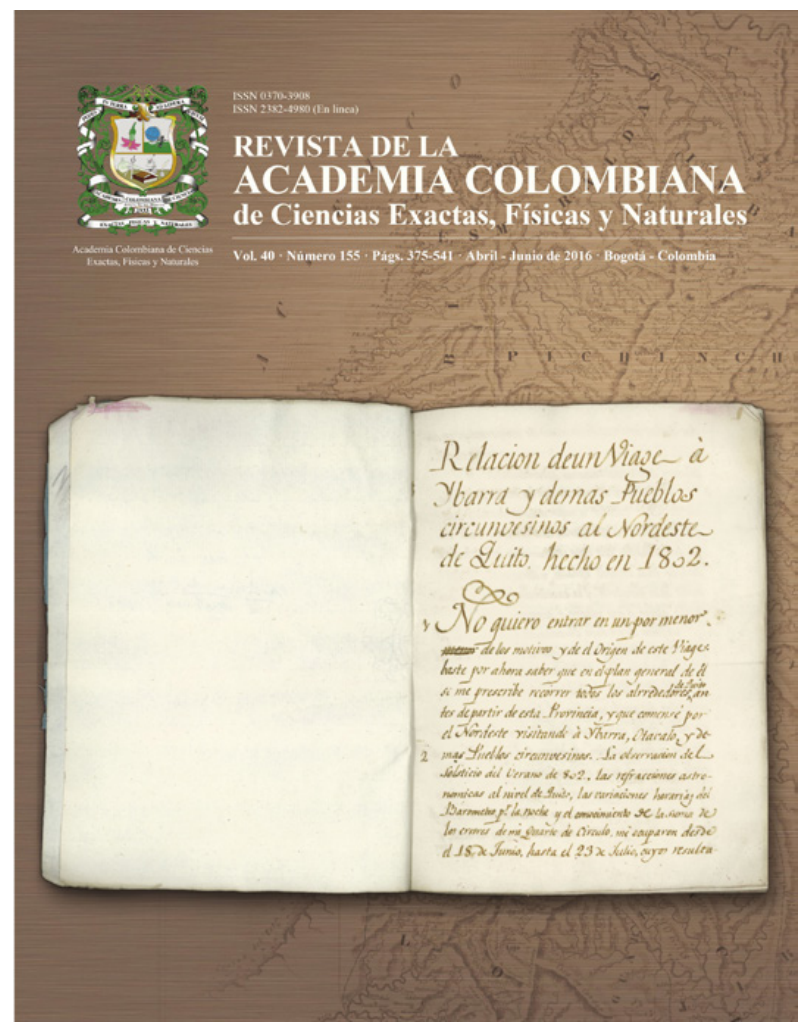

Figura 11. Portada Revista Academia Colombiana de Ciencias Exactas Físicas y Naturales 40(156). Julio-Septiembre 2016.

(Figura 11). Este documento de 118 folios manuscritos y 76 folios en blanco contiene 12 textos diferentes fechados de 1802 a 1807, cuyos títulos son:

1. Relación de un Viage à Ybarra y demas Pueblos circunvesinos al Nordeste de Quito hecho en 1802

2. Trabajos geodésicos sobre Ymbabura

3. Aves

4. Quito

5. Huerto y jardín de Chillo

6. Visita al palacio del marqués de Selva Alegra en Chillo, al sudeste de Quito

7. Viage a las pirámides y bace de Yaruqui

8. Viage a Pichincha

9. Viage al Panecillo

10. Determinación del Término de la Nieve perpetua en las cercanías del Equador

11. Determinación del Término de la Vegetación en las cercanías del Equador

12. Materiales para la Memoria sobre los árboles de Quina

Decíamos en la presentación del manuscrito inédito que la "amplitud temática que revelan estos títulos se amplía considerablemente al seguir folio tras folio su contenido, muy rico en conceptos y mediciones originales. El análisis detallado de cada uno de ellos revelará nuevas apreciaciones de Caldas sobre su entorno en la primera década del siglo XIX, y permitirá fundamentar nuevas hipótesis sobre el alcance de sus trabajos a partir de su vinculación a la Expedición Botánica a mediados de ese mismo año de 1802, cuando aún vivía en los territorios que hoy hacen parte del Ecuador". ${ }^{64}$

Una vez rememorado, con estas tres portadas, el año -en varios sentidos dramático- de la desaparición forzada de uno de los primeros científicos de renombre en nuestro país, y ya iniciando el nuevo año de 2017, apareció en la página 244 del volumen 41 (número 159) de la revista, un artículo escrito por el astrónomo Gregorio Portilla, actual director del Observatorio Astronómico Nacional, quien recordó, en el mismo edificio que inauguró Caldas, la atención que el payanés le prestó allí, 210 años atrás, a un cometa que cruzó el cielo santafereño en $1807 .{ }^{65}$

El profesor Portilla menciona que es poco lo que se ha escrito sobre las ocupaciones específicamente astronómicas de Caldas, y que esto tiene eventualmente una razón de ser puesto que el propio payanés rehuía las ciencias básicas, expresándose, como vimos, sobre una de estas -la astronomía pura-, con displicencia:

Observar el cielo por observarlo sería una ocupación honesta, pero no pasaría de ser una curiosidad estéril que llenase los momentos del hombre ocioso y acomodado [...]: queremos que nuestros trabajos astronómicos mejoren nuestra geografía, nuestros caminos y nuestro comercio. ${ }^{66}$

Caldas, dice Portilla, "contempla la astronomía como una herramienta subsidiaria de la geografía (modernamente diríamos tanto de la geodesia como de la topografía)". A pesar de esto, en aquel año de 1807 Caldas dedicó varias noches -"entre finales de septiembre y al menos hasta inicios de noviembre"- a la observación "estéril" del cometa que hoy se conoce como el cometa "C/1807 R1". $\mathrm{Y}$ sus observaciones quedaron registradas al menos en dos fuentes. La primera, el número "cero" del Semanario del Nuevo Reino de Granada, decía así:

Pareciéndole al Editor interesante y curiosa la siguiente noticia, ha querido publicarla antes de dar principio a su Semanario. Desde el 23 de setiembre se advirtió al fin de la constelación de la Virgen un cometa, y se comenzó a observar el 25 en el Observatorio astronómico de esta Capital. El encargado de este establecimiento D. Francisco Joseph de Caldas, ha comenzado una serie de observaciones, y el 26 fijó el lugar del nuevo astro para $6^{\text {hor[as] }} 37^{\text {min[utos] }} 17^{\text {seg[undos] }}$, tiempo verdadero del meridiano del Observatorio: el resultado fue

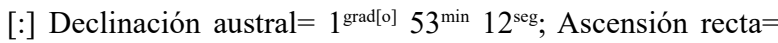
$217^{\text {grad }} 57^{\mathrm{min}} 0^{\text {seg }}$; Longitud geocént $[$ rica $]=7^{\text {sig[ma] }} 6^{\text {grad }} 19^{\text {min }}$ $59^{\text {seg; }}$ Latitud boreal $=12^{\text {grad }} 25^{\mathrm{min}} 25^{\text {seg }}$.

El cuerpo del cometa pareció bastante terminado, y del diámetro de Marte poco más o menos. Su luz era rojiza, débil, y como dentro de nieblas. El núcleo estaba rodeado

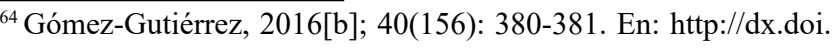
org/10.18257/raccefyn.413

${ }^{65}$ Portilla, 2017; 41(159): 244-252. En: http://dx.doi.org/10.18257/ raccefyn. 449

${ }^{66}$ Ibidem, 245.
} 
de una atmósfera luminosa prolongada en abanico hacia la parte opuesta al Sol, y cuya fuerza disminuía por grados insensibles hasta desaparecer. Esta ráfaga de luz, que puede llamarse barba por preceder al cometa en su curso era oblicua, y seguía la dirección de la Eclíptica; en fin, su longitud pareció de 38 a 40 minutos. Las observaciones que se han hecho, y que siguen haciéndose en el Observatorio, nos enseñarán el curso, distancia, órbita, etc. de este bello cometa. D. Francisco Joseph de Caldas se propone seguirle hasta su desaparición, e informar al público del resultado de sus trabajos. Mucho ha sentido este observador no haberlo advertido antes, pero procurará llenar este vacío con las numerosas observaciones que actualmente ejecuta. ${ }^{67}$

La segunda, carta de Caldas a Santiago Pérez de Arroyo y Valencia (1773-1845), firmada el 6 de noviembre de 1807, trae mayores precisiones sobre la trayectoria del cometa:

Es verdad que este astro ha llenado mis momentos ha más de un mes, y creo no le dejaré hasta su total desaparición. El tiempo falta para calcular todos los elementos de mis observaciones; pero las verá con el tiempo. Desde su aparición ha disminuido constantemente de diámetro y de luz. La cola que estaba en la inclinación de la eclíptica el 23 de septiembre, está hoy al contrario y vuelta al Norte. El abanico que formaba se ha dilatado más; esta es la forma que hoy tiene. Su curso es bien caprichoso; se vio en Virgo, cortó el ecuador entre el 28 y 29 de septiembre, pasó al Monte Menelao, tocó en la cabeza del Serpentario, y está ahora sobre el dorso de Hércules. Quién sabe dónde desaparecerá! $!^{68}$

En carta escrita al mismo corresponsal exactamente tres meses después, le revela un detalle más íntimo: "Mi cabeza padeció con el cometa y ya estoy restableciéndome". ${ }^{69}$

Una tercera fuente, aportada por el profesor Portilla, el número 32 de El Redactor Americano del Nuevo Reino de Granada publicado en marzo 19 de 1808, revela la fecha de las primeras observaciones de este cometa en Santafé y en Cartagena, tal y como fueron reportadas por neogranadinos anónimos:

Me consta que, sin instrumento alguno, y sólo con la simple vista lo percibió desde el diez de septiembre un sujeto de esta ciudad de Santafé, y también otro en la de Cartagena, según carta remitida de allí. $^{70}$

El artículo del actual director del Observatorio Astronómico Nacional concluye que a Caldas le corresponde el mérito de haber observado muy temprano el cometa C/1807 R1 y de haber fijado de manera precisa sus coordenadas, $\mathrm{y}$ aporta, motu proprio, una reconstrucción gráfica del cielo que pudo observar Caldas el 26 de septiembre de 1807, primer día que, según su reporte, pudo observar el cometa en Santafé (Figura 12). ${ }^{71}$

\footnotetext{
${ }^{67}$ Ibidem, 246-247. Citado a partir de Caldas [1807] 1978, s.p.

${ }^{68}$ Ibidem, 247. Citado a partir de Caldas [1807], en Bateman y Arias, 1978, 264.

${ }^{69}$ Ibidem, 247. Citado a partir de Caldas [1807], en Savitskaya y Caldas Varona, 2016, 279.

${ }^{70}$ Ibidem, 247.

${ }^{71}$ Tomado de: Ibidem, 248.
}

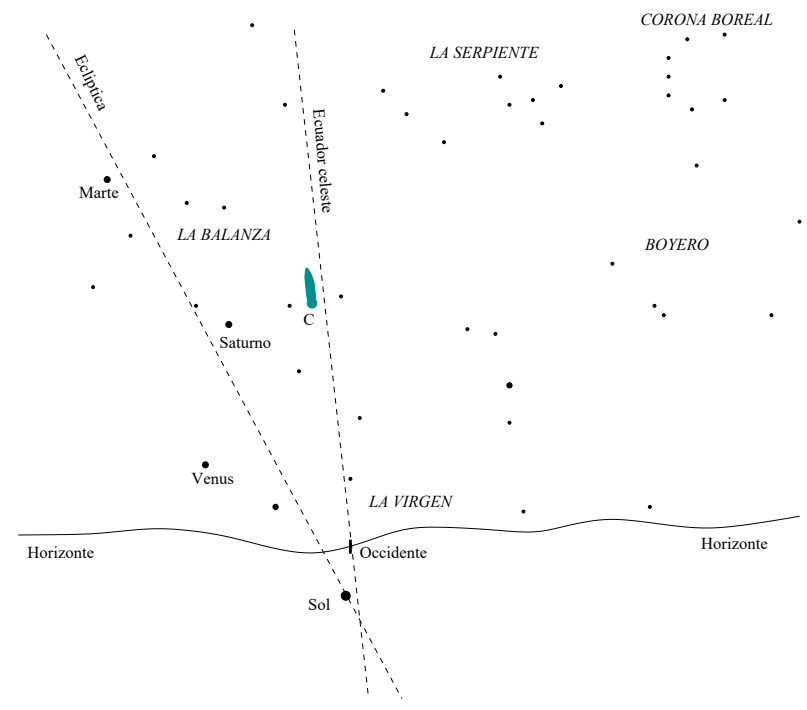

Figura 12. Posición del cometa [C/1807 R1] (C) en el horizonte occidental para un observador ubicado en Santafé de Bogotá a las $18^{h} 28^{m} 41^{s}$ (tiempo solar medio referido al meridiano del Observatorio Astronómico) del día 26 de septiembre de 1807. El horizonte, que se ha descrito como una curva continua ondulada, no representa el horizonte real.

Hasta aquí lo publicado sobre Caldas entre 1936 y 2017 en la Revista de la Academia Colombiana de Ciencias Exactas, Físicas y Naturales.

\section{Conclusiones}

Las versiones originales de cada uno de los artículos referidos en la presente antología se incluyen a continuación en versión facsimilar, y pueden consultarse en línea en www. raccefyn.co. Así, el lector contemporáneo podrá disponer fácilmente de las fuentes que contienen cada concepto que ha sido referido en la pluma de los académicos sobre la vida y obra de Francisco José de Caldas, tal y como quedó inscrito en esta revista. De la misma manera, la historiografía crítica podrá considerar el papel de la Academia en la selección y compilación de estas fuentes con el propósito de construir una identidad particular en torno a uno de los primeros científicos de nuestro territorio.

\section{Agradecimientos}

Debo agradecer la lectura detenida del presente texto y las sugerencias de José Antonio Amaya, así como los comentarios de Luis Carlos Arboleda, Darío Valencia y Mauricio Nieto, con quienes compartí la mesa de ponentes de la primera sesión del Seminario de Estudios Caldasianos en la Academia Colombiana de Ciencias Exactas, Físicas y Naturales en el mes de marzo de 2018. Finalmente, y de manera muy especial, quisiera registrar la generosa disposición del profesor Jorge Arias de Greiff en sucesivas conversaciones sobre Caldas y otros viajeros de las que he podido disfrutar en público y en privado en el curso de los últimos años. 


\section{Referencias}

Amaya, J. A. (2004). Cuestionamientos internos e impugnaciones desde el flanco militar a la Expedición Botánica. Anuario Colombiano de Historia Social y de la Cultura. 31: 75-118.

Albis González, V. S. \& Martínez-Chavanz, R. (2016). Las investigaciones meteorológicas de Caldas. En: Valencia Restrepo, Darío (ed.). Ensayo de una memoria sobre un nuevo método de medir las montañas por medio del termómetro. Medellín: Universidad de Antioquia. p. 65-77.

Álvarez Lleras, J. La quinología de Caldas y un nuevo aspecto científico de este prócer. Revista de la Academia Colombiana de Ciencias Exactas, Físicas y Naturales. 1937; 1 (4): 306-309.

Álvarez Lleras, J. (1938). Los escritos de Caldas. Revista de la Academia Colombiana de Ciencias Exactas, Físicas y Naturales. 2 (5): 2-3.

Álvarez Lleras, J. (1938). Notas de la dirección. Revista de la Academia Colombiana de Ciencias Exactas, Físicas y Naturales. 2 (6): 161-177.

Álvarez Lleras, J. (1938). Nota de la dirección. Revista de la Academia Colombiana de Ciencias Exactas, Físicas y Naturales. 2 (6): 206.

Álvarez Lleras, J. (1945). Sesión solemne de la Sociedad Colombiana de Ingenieros en honor de Caldas. Revista de la Academia Colombiana de Ciencias Exactas, Físicas y Naturales. 6 (22-23): 400-403.

Álvarez Lleras, J. (1951). Homenaje al sabio Francisco José de Caldas. Revista de la Academia Colombiana de Ciencias Exactas, Físicas y Naturales. 8 (30): 145-146.

Andrade, G. (2016). Las mariposas de Francisco José de Caldas y Thenorio. Revista de la Academia Colombiana de Ciencias Exactas, Físicas y Naturales. 40 (155): 190-191.

Andress, R (ed.) \& Nieto Olarte, M. (2013). Diario de viajes de Francisco José de Caldas. Sevilla: Consejo Superior de Investigaciones Científicas. p. 356.

Appel, J. W. (1994). Francisco José de Caldas. A scientist at work in Nueva Granada. Transactions of the American Philosophical Society. 84 (5): 1-153.

Arboleda, L. C., Díaz-Piedrahita, S., Molinos, R. (editores). (1994). Francisco José de Caldas. Bogotá: Molinos Velázquez Editores. p. 158.

Arboleda, L. C. (2016). Caldas, matematización de la naturaleza y sentimiento telúrico. Revista de la Academia Colombiana de Ciencias Exactas, Físicas y Naturales. 40 (154): 6-7.

Arboleda, L. C. (2016). Caldas y la matematización de la naturaleza. La querella con Humboldt sobre el hipsómetro. En: Valencia Restrepo, Darío (ed.). Ensayo de una memoria sobre un nuevo método de medir las montañas por medio del termómetro. Medellín: Universidad de Antioquia. p. 145-166.

Arias de Greiff, J., Bateman, A., Fernández Pérez, Á. \& Soriano Lleras, A. (editores). (1966). Obras completas de Francisco José de Caldas. Bogotá: Universidad Nacional de Colombia - Imprenta Nacional. p. 530.

Arias de Greiff, J. (1974). Algunos documentos, desconocidos unos, y poco conocidos otros, pertinentes a don Francisco José de Caldas y Tenorio. Boletín de Historia y Antigüedades. 61 (704): 187-200.

Arias de Greiff, J. (1994). Francisco Josef de Caldas y Thenorio. En: Arboleda, Luis Carlos; Díaz-Piedrahita, Santiago; Molinos, Rosario (editores). Francisco José de Caldas. Bogotá: Molinos Velázquez Editores. p. 11-21.
Arias de Greiff, J. (1994). Caldas: inquietudes, proyectos y tragedias. En: Arboleda, Luis Carlos; Díaz-Piedrahita, Santiago; Molinos, Rosario (editores). Francisco José de Caldas. Bogotá: Molinos Velázquez Editores. p. 37-53.

Arias de Greiff, J. (1996). El método de Caldas para medir la elevación de las montañas. Revista de la Academia Colombiana de Ciencias Exactas, Físicas y Naturales. 20 (76): 63-69.

Arias de Greiff, J. (2016). El método de Caldas para medir la elevación de las montañas. En: Valencia Restrepo, Darío (ed.). Ensayo de una memoria sobre un nuevo método de medir las montañas por medio del termómetro. Medellín: Universidad de Antioquia. p. 99-113.

Barreiro, A. (1933). Relación de un viaje hecho a Cotacache, La Villa, Imbabura, Cayambe, etc., comenzado el 23 de julio de 1802, por Francisco José de Caldas. Madrid: Librería General de Victoriano Suárez. p. 214.

Bateman, A. D. (1952). Caldas y el hipsómetro. Revista de la Academia Colombiana de Ciencias Exactas, Físicas y Naturales. 8 (32): 449-457.

Bateman, A. D. (1959). Caldas y Humboldt. Revista de la Academia Colombiana de Ciencias Exactas, Físicas y Naturales. 10 (41): 59-67.

Bateman, A. D. (1969). Francisco José de Caldas. Síntesis biográfica. Bogotá: Academia Colombiana de Historia. p. 112.

Bateman, A. D. (1970). Francisco José de Caldas. Selección de obras. Bogotá: Schering. p. 233.

Bateman, A. D. 1978. Francisco José de Caldas. El hombre y el sabio. Su vida - Su obra. Cali: Banco Popular. p. 427.

Bateman, A. D. \& Arias de Greiff, J. (editores). (1978). Cartas de Caldas. Bogotá: Academia Colombiana de Ciencias Exactas, Físicas y Naturales. p. 425.

Caldas, F. J. (1937). Memoria sobre el estado de las quinas en general y en particular sobre las de Loja. Revista de la Academia Colombiana de Ciencias Exactas, Físicas y Naturales [1805]. 1 (4): 326-333.

Caldas, F. J. (1938). Copia de una carta inédita del sabio Caldas al doctor Antonio Arboleda, de Popayán. Revista de la Academia Colombiana de Ciencias Exactas, Físicas y Naturales [1802]. 2 (5): 3-5.

Caldas, F J. (1938). Estudios seleccionados referentes a astronomía, meteorología y física. Revista de la Academia Colombiana de Ciencias Exactas, Físicas y Naturales [1802-1811]. 2 (6): 178-206.

Caldas, F. J. (1938). Artículo necrológico del Sr Dr José Celestino Mutis. Revista de la Academia Colombiana de Ciencias Exactas, Físicas y Naturales [1808]. 2 (6): 327-329.

Caldas, F. J. (1938). Explicación de Caldas referente a la lápida de Cuenca. Revista de la Academia Colombiana de Ciencias Exactas, Físicas y Naturales [1804]. 2 (6): 311-313.

Caldas, F. J.. (1950). Prefacio [a la geografía de las plantas de Alexander von Humboldt]. Revista de la Academia Colombiana de Ciencias Exactas, Físicas y Naturales [1809]. 8 (29): 65-66.

Caldas, F. J. Provincias Unidas de la Nueva Granada. De orden del Gobierno General por el C[iudada]no. Francisco José de Caldas, Coronel del Cuerpo Nacional de Yngenieros, lámina 13. p. 125. Tomada de: http://www.colombiaaprende. edu.co/html/mediateca/1607/article-239570.html

Cañizares-Esguerra, J. (2005). How derivative was Humboldt? Microcosmic nature narratives in early modern Spanish America and the (other) origins of Humboldt's ecological 
sensibilities. En: Schiebinger, Londa and Swan, Claudia (editores). Colonial botany: science, commerce and politics in the early modern world. Philadelphia: University of Pennsylvania Press. p. 148-165.

Castrillón, A. (1997). Fitogeografía, paisaje y territorialidad al comienzo del siglo XIX. Boletín Cultural y Bibliográfico. 34 (46): 60-84.

Caycedo, B. J. (1951). Grandezas y miserias de dos derrotas. Bogotá: Editorial Voluntad. p. 227.

Chenu, J. (1992). Francisco José de Caldas. Un peregrino de las ciencias. Madrid: Historia 16. p. 357.

Cuartas Chacón, C. J. (2016). El sabio Caldas: homenaje en el bicentenario de su fallecimiento. Bogotá: Pontificia Universidad Javeriana - Grupo Editorial Ibáñez. p. 132.

Díaz Cueva, M. (1988). La lápida de Tarqui. Quito: Comisión Nacional Permanente de Comisiones Cívicas - Casa de la Cultura Ecuatoriana. p. 120.

Díaz-Piedrahita, S. (1992). Francisco José de Caldas y la botánica. Revista de la Academia Colombiana de Ciencias Exactas, Físicas y Naturales. 18 (70): 369-382.

Díaz-Piedrahita, S. (1994). Caldas y la historia natural. En: Arboleda, Luis Carlos; Díaz-Piedrahita, Santiago; Molinos, Rosario (editores). Francisco José de Caldas. Bogotá: Molinos Velázquez Editores. p. 111-123.

Díaz-Piedrahita, S. (1997). Nueva aproximación a Francisco José de Caldas. Episodios de su vida y de su actividad científica. Bogotá: Academia Colombiana de Historia. p. 295.

Ebach, M. C. (2015). Origins of Biogeography. The role of biological classification in early plant and animal geography. Dordrecht: Springer. p. 172.

Fernández Pérez, Á. (1955). Año y lugar de nacimiento de Francisco José de Caldas. Caldasia. VII (31): 3-6.

Gómez-Gutiérrez, A. (2015 [a]). Alexander von Humboldt y la cooperación transcontinental en la Geografía de las plantas: una nueva aproximación a la obra fitogeográfica de Francisco José de Caldas. Internationale Zeitschrift für Humboldt-Studien. 17 (33): 22-49.

Gómez-Gutiérrez, A. (2016 [b]). Un manuscrito póstumo e inédito de 200 años: Cuaderno de viajes y observaciones de Francisco José de Caldas entre 1802 y 1807. Revista de la Academia Colombiana de Ciencias Exactas, Físicas y Naturales. 40 (156): 380-381.

Gómez, M. B. (ed.) \& Amaya, J. A. (2002). Francisco José de Caldas. El mercader que escrutaba las estrellas. Serie Cuadernos Iconográficos, $n^{\circ}$ 3. Bogotá: Museo Nacional de Colombia. p. 38 .

González-Orozco, C. E., Ebach, M. C., Varona, R. (2015). Francisco José de Caldas and the early development of plant geography. Journal of Biogeography. 42 (11): 2023-30.

Gutiérrez Ardila. D. (2016). La restauración en la Nueva Granada (1815-1819). Bogotá: Universidad Externado de Colombia. p. 300 .

Humboldt, A. von. (1992). Alexander von Humboldt en Colombia. Extractos de sus diarios. Auswahl aus seinen Tagebuchern. Edición bilingüe. Academia Colombiana de Ciencias Exactas, Físicas y Naturales - Academia de Ciencias de la República Democrática Alemana. Bogotá: Publicismo Ediciones. p. 300.

Martínez Delgado, L. \& Ortiz, S. E. (1960). Francisco José de Caldas, periodista. Revista de la Academia Colombiana de Ciencias Exactas, Físicas y Naturales. 11 (42): XXXIXXXVI.
Mendoza Pérez, D. (1909). Expedición Botánica de José Celestino Mutis al Nuevo Reino de Granada y memorias inéditas de Francisco José de Caldas. Madrid: Victoriano Suárez. p. 297.

Murillo, L. M. (1951). El amor y la sabiduría de Francisco José de Caldas. Revista de la Academia Colombiana de Ciencias Exactas, Físicas y Naturales. 8 (30): 149-153.

Murillo, L. M. (1960). Francisco José de Caldas. Revista de la Academia Colombiana de Ciencias Exactas, Físicas y Naturales. 11 (42): VII-XV.

Nieto Olarte, M. (2006). La obra cartográfica original de Francisco José de Caldas. Bogotá: Universidad de los Andes - Academia Colombiana de Historia - Academia Colombiana de Ciencias Exactas, Físicas y Naturales Instituto Colombiano de Antropología e Historia. p. 186.

Nieto Olarte, M. (2007). Orden natural y orden social. Ciencia y política en el Semanario del Nuevo Reyno de Granada. Bogotá: Ediciones Uniandes. p. 436.

Nieto Olarte, M. (2010). Americanismo y eurocentrismo. Alexander von Humboldt y su paso por el Nuevo Reino de Granada. Bogotá: Ediciones Uniandes. p. 118.

Nieto, M. (editor). (2016). Memoria histórica sobre la vida, carácter, trabajos científicos i literarios, i servicios patrióticos de Francisco José de Caldas. Bogotá: Instituto Caro y Cuervo. p. 93.

Pérez Arbeláez, E. (1959). La ciencia y la historia. Revista de la Academia Colombiana de Ciencias Exactas, Físicas y Naturales. 10 (41): 69-72.

Pombo, L. de. (1938). Memoria histórica sobre la vida, carácter, trabajos científicos y literarios, y servicios patrióticos de Francisco José de Caldas. Revista de la Academia Colombiana de Ciencias Exactas, Físicas y Naturales [1852]. 2 (6): 329-337.

Pombo, L. de. (1951). [Era Caldas...]. Revista de la Academia Colombiana de Ciencias Exactas, Físicas y Naturales [1852]. 8 (30): inserto.

Portilla, J. G. (2017). Caldas y el gran cometa de 1807. Revista de la Academia Colombiana de Ciencias Exactas, Físicas y Naturales. 41 (159): 244-252.

Posada, E. (compilador). (1912). Obras de Caldas. Bogotá: Academia Colombiana de Historia. p. 596.

Posada, E. (compilador). (1917). Cartas de Caldas. Bogotá: Academia Colombiana de Historia. p. 512.

Puerta Olaya, M. A. \& Escobar Ortiz, J. M. (2017). Botánica y topografía: el problema de la nivelación de las plantas en la historiografía científica sobre Francisco José de Caldas. Historia y Sociedad. 33: 77-109.

Savitskaya, N. \& Caldas Varona, D. (editores). (2016). Cartas de Caldas ilustradas. Bogotá: Universidad Distrital Francisco José de Caldas - Casa Museo Caldas - Academia Colombiana de Ciencias Exactas, Físicas y Naturales. p. 548.

Schumacher, H. (1986). Caldas. Un forjador de la cultura. Bogotá: Empresa Colombiana de Petróleos [1884]. p. 256.

Valencia Restrepo, D. (editor). (2016[a]). Ensayo de una memoria sobre un nuevo método de medir las montañas por medio del termómetro. Medellín: Universidad de Antioquia-Academia Colombiana de Ciencias Exactas, Físicas y Naturales. p. 166.

Valencia Restrepo, D. (editor). (2016[b]). Francisco José de Caldas, 1768-1816. Bicentenario de su muerte. Medellín: Universidad de Antioquia - Academia Colombiana de Ciencias Exactas, Físicas y Naturales - Parque Explora Universidad Nacional de Colombia - Acofi. p. 196. 
Valencia Restrepo, D. (2016[c]). Francisco José de Caldas. Lecturas de ida y vuelta. Medellín: Confama - Metro de Medellín. p. 114.

Valencia Restrepo, D. (2018). Contribución de Caldas a la fundación de la geografía de las Plantas. Revista Aleph. LII (185): 5-25.
Vila, P. (1960). Caldas y los orígenes eurocriollos de la geobotánica. Revista de la Academia Colombiana de Ciencias Exactas, Físicas y Naturales. 11 (42): XVI-XX.

Villacrés Moscoso, J. (1986). Las aventuras de los geodestas franceses del siglo XVIII en la región amazónica. Guayaquil: Universidad de Guayaquil. p. 146. 